\title{
Knowledge-Based Prediction of Load-Carrying Capacity of RC Flat Slab through Neural Network and FEM
}

\author{
Afaq Ahmad (i), ${ }^{1}$ Muhammad Usman Arshid $\left(D^{\circ},{ }^{1}\right.$ Toqeer Mahmood $\left(D,{ }^{2}\right.$ Naveed Ahmad $(D)$, \\ Abdul Waheed $\mathbb{D}^{3},{ }^{3}$ and Syed Shujaa Safdar $\mathbb{D}^{4}$ \\ ${ }^{1}$ Department of Civil Engineering, University of Engineering and Technology, Taxila-47050, Pakistan \\ ${ }^{2}$ Department of Computer Science, National Textile University, Faisalabad-37610, Pakistan \\ ${ }^{3}$ MCE, National University of Science and Technology, Islamabad-44000, Pakistan \\ ${ }^{4}$ Department of Civil Engineering, Capital University of Science \& Technology, Islamabad-44000, Pakistan
}

Correspondence should be addressed to Toqeer Mahmood; toqeer.mahmood@yahoo.com

Received 23 June 2021; Revised 1 September 2021; Accepted 14 September 2021; Published 29 September 2021

Academic Editor: Danial Armaghani

Copyright (C) 2021 Afaq Ahmad et al. This is an open access article distributed under the Creative Commons Attribution License, which permits unrestricted use, distribution, and reproduction in any medium, provided the original work is properly cited.

\begin{abstract}
The present research work aims to compare the results for predicting the ultimate response of Reinforced Concrete (RC) members using Current Design Codes (CDCs), an alternative method based on the Compressive Force Path (CFP) method, and Artificial Neural Network (ANN). For this purpose, the database of 145 samples of RC Flat Slab with the simple supported condition under concentrated load is developed from the latest published work. All the cases studied were Square Concrete Slabs (SCS). The critical parameters used as input for the study were column dimension, $c_{s}$, depth of the slab, $d_{s}$, shear span ratio, $a_{v s} / d$, longitudinal percentage steel ratio, $\rho_{l s}$, yield strength of longitudinal steel, $f_{y l s}$, the compressive strength of concrete, $f_{c s}$, and ultimate loadcarrying capacity, $V_{u s}$. Seven ANN models were trained using different combinations of input parameters and different points of hidden neurons with different activation functions. The results exhibited that SCS- 4 was the most optimized ANN model, having the maximum value of $R(89 \%)$ with the least values of MSE $(0.62 \%)$ and MAE (6.2\%). It did not only reduce the error but also predicted accurate results with the least quantity of input parameters. The predictions obtained from the studied models (i.e., CDCs, CFP, and ANN) exhibited that results obtained using the ANNs model correlated well with the experimental data. Furthermore, the FEM results for the selected cases show the closer result to the ANN predictions.
\end{abstract}

\section{Introduction}

The practice of Reinforced Concrete (RC) flat slabs or flat plate or waffle slabs in which the RC slab is placed directly over the RC members (as explained in Figure 1) is very common in the construction industry. It improves the structural flexibility and reduces the overall height of the structure, facilitating the provision of an additional number of floors (as illustrated in Figure 2). It also makes construction easier by reducing the shuttering time and relevant costs. However, due to the direct placement of RC slab over columns and because of its simple shape, the flat slabs are more vulnerable to a sudden or punching failure [1]. Hentschel [1] provided a detailed explanation of the work done in the year 2001-2005 about the problem of punching failure of RC flat under monotonic uploads. The other researchers also worked on the validity of these methods by comparing their results with the experimental values and developed a database with the important information of all critical parameters that accounted for the punching failure $[2,3]$.

The actual construction of slab-column connection is an important problem in the construction of RC flat slab structures due to difficulties related to operating services and higher concentration of structural load in the slab-column region (as shown in Figure 3(a)). Such load concentration in the vicinity of slab-column joint may result in shear failure especially on the $2 \mathrm{D}$ members $[2,3]$. This type of concretebased failure causes a rapid failure without noteworthy warning (as illustrated in Figure 3(b)), indicating the 


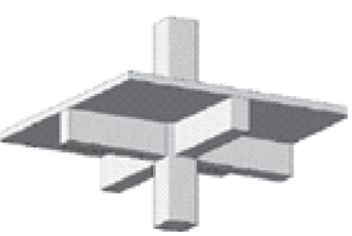

(a)

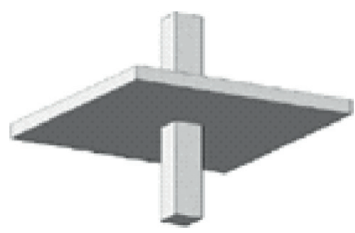

(b)

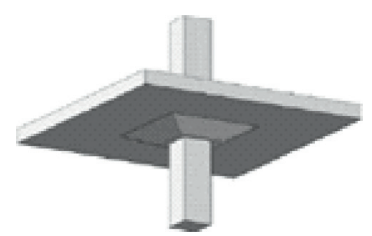

(c)

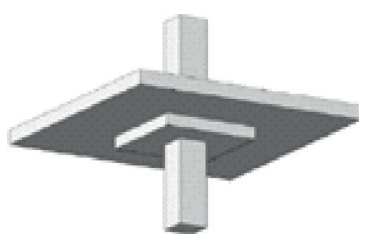

(d)

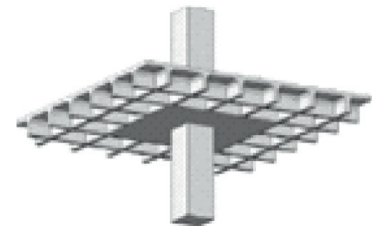

(e)

Figure 1: (a) Slab on RC beam. (b) Flat slab on column. (c) Flat slab on capital. (d) Flat slab on drop panel. (e) Waffle slab on RC ribs [4].

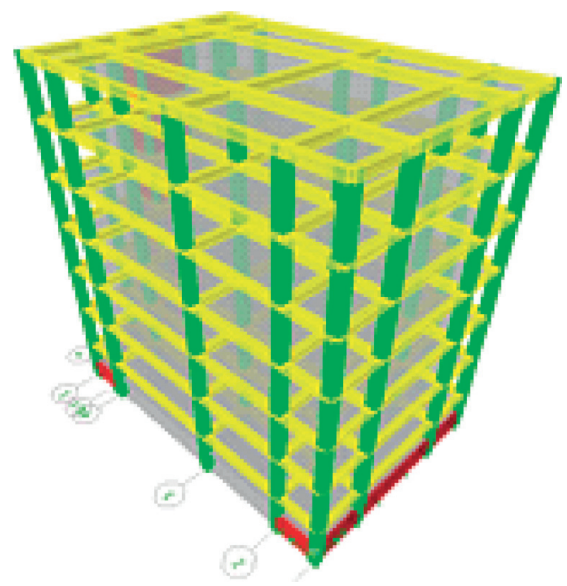

(a)

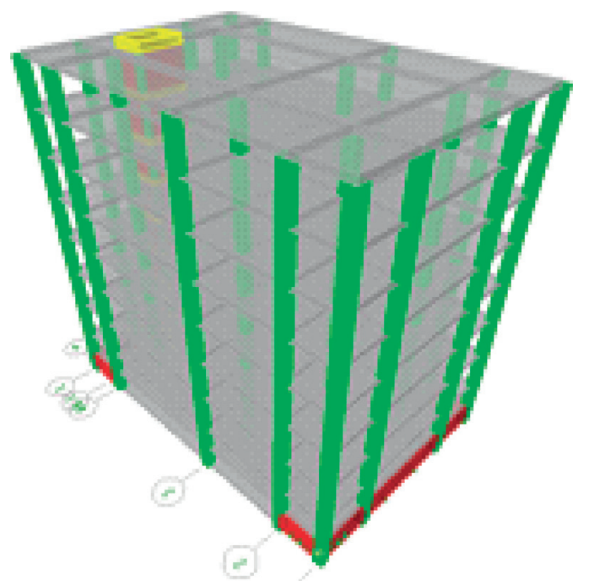

(b)

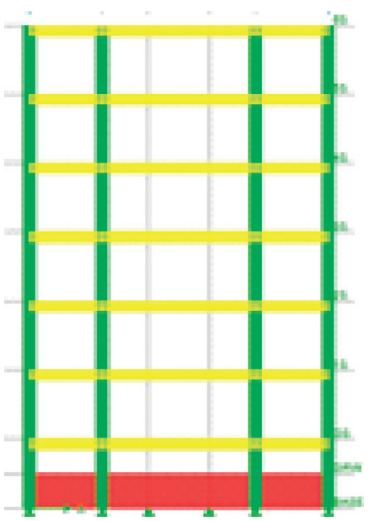

(c)

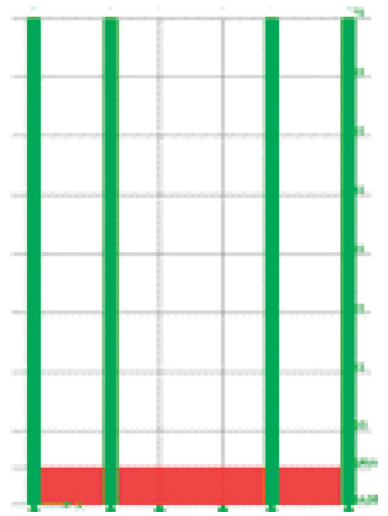

(d)

FIgURE 2: (a) Building 3D view with RC beam slab with (b) front elevation. (c) Building 3D view with RC flat slab with (d) front elevation.

succeeding collapse of the part of the car parking building at Wolverhampton $[4,5]$.

In current design practice, there are certain doubts regarding the use of flat slabs in earthquake-resistant RC structures. The requirements of Eurocode $8[2,3]$ do not include the case of flat slab or flat plate supported on RC members as part of the resisting system against the lateral loading. On the contrary, ACI $318[2,3]$ includes guidelines for the analysis and assessment of RC flat slabs as part of an "intermediate moment frame" but excludes them from use in "special moment frames" [2,3]. The results of insufficient predicting behavior by current design codes were experienced in different earthquake events [2,3]. In an attempt to satisfy the above need, the alternative new design methodology known as the Compressive Force Path (CFP) methodology [6] is used in this comparative study. In 


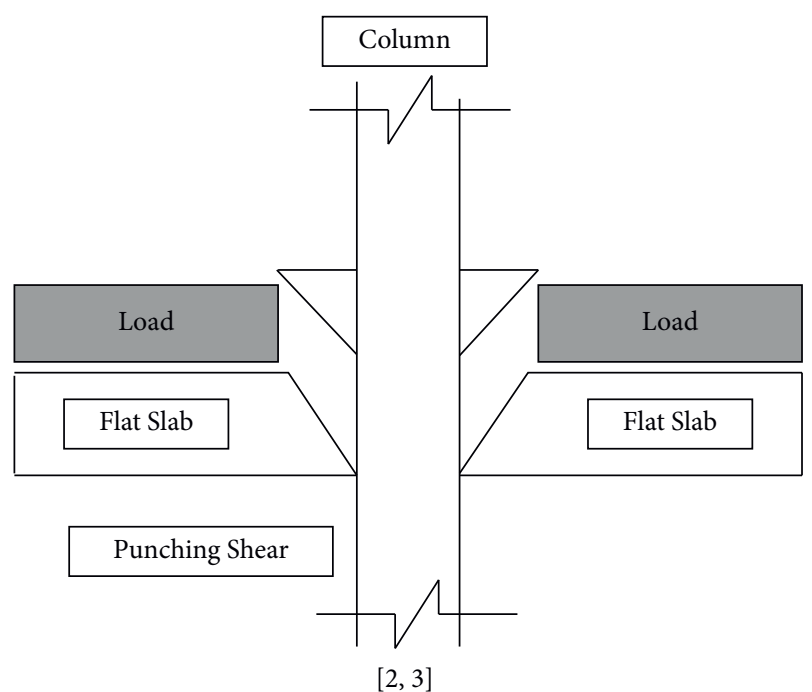

(a)

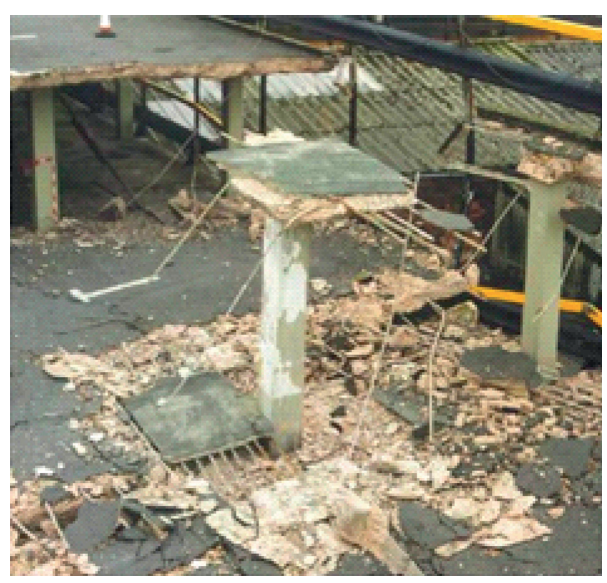

(b)

FIgURE 3: Formation of (a) failure cone and (b) example of Wolverhampton car parking slab.

comparison with the CDCs, the CFP methodology is based on the use of simple failure criteria. Although the latter criteria are developed from primary assumptions while excluding the requirement of the test data, their efficiency for evaluating shear capacity based on lab data is less than that of CDCs but they provide a reasonable indication for the causes and location of punching initiation. Moreover, the experimental verification of the method has shown that, in comparison with CDCs, it is capable of providing design results that fully satisfy the routine requirements of CDCs for the design of earthquake-resistant RC structures $[2,3]$.

Artificial Neural Network (ANN) is inconsistent and inclined to develop strange connections among system variables, even if they are unaware of the type of interaction [7-11], which do not depend on the underlying mechanism assumptions [12-15]. In the last two decades, the use of Soft Computing (SC) methods to solve complex problems has been proposed by many researchers [16-35]. In this work, response of both complex and simple reinforced concrete members at ULR has been assessed by using CDC, CFP, and ANN techniques. In previous studies, ANNs have been used to estimate material behavior [36-39] as well as response of RC members $[11,40-48]$. ANNs have achieved the advanced attention of the researcher for solving the problems, especially for estimating the ULR of composite concrete members (CCM) [49-51]. Also, load-carrying capacity of advance materials has been predicted using ANNs as discussed in the articles [52-75]. The other technique to determine the ultimate response of the RC members with FRP rebars is finite element analysis (FEA). The literature showed that many researchers worked on the FEM studies [76-80]. Also, load-carrying capacity of some advance materials has been predicted using FEM [81, 82].

The present work aims to compare the results obtained by using Compressive Force Path method (CFP), Current Design Codes (CDCs), and Artificial Neural Network
(ANN) for estimating the response of the reinforced concrete (RC) Members at ULR. The comparative study exhibited that these codes predicted the underestimated values [11, 40-48]. Therefore, in this study, ANN models have been developed for predicting real load-carrying capacity of reinforced concrete flat slab. For this purpose, data for 145 samples of Square Concrete Slabs (SCSs) tested under concentric loading was collected from previous studies. The data included all the detailed information of column dimension, $c_{s}$, depth of the slab, $d_{s}$, shear span ratio, $a_{v s} / d$, longitudinal percentage steel ratio, $\rho_{l s}$, yield strength of longitudinal steel, $f_{y l s}$, compressive strength of concrete, $f_{c s}$, and ultimate load-carrying capacity, $V_{u s}$. Seven ANN models were developed and an optimized model was selected based on maximum $\mathrm{R}$ value, higher prediction level, and minimum MSE, MAE, and error values. (i.e., SCS $-4 c_{s} / d_{s}, a_{v s} / d, \rho_{l s}$, and $\left.f_{c s} / f_{y s}\right)$. Also, the predicted best model (i.e., SCS-4) exhibited reasonable accurate results to the lab values as compared to other counterparts i.e., CDCs. Furthermore, finite element modeling (FEM) is also carried out for the validation of the ANN prediction, for the selected cases. The FEA results are within reasonable limits with the experimental values and ANN results.

\section{Physical Models for RC Flat Slab}

The theory providing the base for load transfer at the ultimate limit response (ULR) of SCS, as available in current design handbooks, is constructed on the mechanics "Truss Analogy" models [40]. The equations of these design codes EC2 and ACI $[2,3]$ are empirical in nature, which varies to the data fitting and may result in failure such as the collapse of structures [5] (as shown in Figures 3(a) and 3(b)). However, the calculations of the CDCs appear to be significantly different from their counterpart experimental values. The major reason for this is the different nature of the analysis formulas used in the CDCs. However, these CDCs 
are used by professionals in engineering to test the capability of the flat slab-column connection at the ULR due to the ease of construction.

The CDCs assumptions [2,3] have been based so far on the discussion of various models and their application to predict the response of the SCS at ULR. These models are based on a few important parameters i.e., column dimension, $c_{s}$, depth of the slab, $d_{s}$, shear span ratio, $a_{v s} / d$, longitudinal percentage steel ratio, $\rho_{l s}$, yield strength of longitudinal steel, $f_{y l s}$, compressive strength of concrete, $f_{c s}$, and ultimate load-carrying capacity, $V_{u s}$, accounted for the punching failure of SCS. The equation used in the ACI 318 [3] for predicting the SCS response as shown in Figure 4(a) is

$$
V_{r c}=\frac{1}{3} * u_{2 s} * d s * \sqrt{f_{c}^{\prime}}
$$

where

$$
\mathbf{u}_{2 \mathbf{s}}=4(\mathbf{c}+\mathbf{d}) \text {. }
$$

And, the equation used in the EC2 [2] for predicting the SCS response as shown in Figure 4(b) is

$$
V_{r c}=0.18 * u_{1} * d *\left(1+\sqrt{\frac{200}{d}}\right) * \sqrt[3]{100 * f_{c}^{\prime} * \rho s}
$$

where

$$
\rho s=\sqrt{\rho_{x} \rho_{y}} \text {, and } \rho_{x}, \rho_{y},
$$

where $\rho_{x}$ is the steel ratio along the $x$-direction of slab and $\rho_{y}$ is the steel ratio along the $y$-direction of slab.

Beside the Truss Analogy (TA) methodology for the CDCs, the other counterpart theory is the CFP method [6] based on the an arch-like frame structure response at ULR [6] and illustrated in Figure 5, which is described by following equations:

$$
\begin{aligned}
w_{I I, 2} & =W_{C}+\left(2 \lambda_{c} d\right), \\
\lambda^{c} & =2-\left[\frac{100 \rho_{l} f_{y}}{500}\right]\left[1+0.01\left(f_{c}-60\right)\right] .
\end{aligned}
$$

\section{Artificial Neural Network (ANN)}

Neural networks simulate the human and animal nervous systems functioning on important information in the brain $[8,83,84]$. These networks are performed to assess the purposes based on extensive given information. ANNs can acquire, classify, summarize, and guess the assigned task because they can keep the information presented to them during the training process into their memory and also because of their adaptability. They are composed of numerous connected layers, each of which contains the interconnected neuron system. There is a tie (having numerical value) between every two neurons in continuous layers, as shown in Figure 6. The prediction made by the neuron is multiplied by these weights. In this latter process, the prediction of the neuron is passed through the link and is added to the bias, as shown in Figure 6. An ANN created on the experience of the
Multilayer Feedforward ANN (MLFNN) is considered to be the most suitable for these types of problems. MLFNN has an input (information) layer, an output (target) layer, and one or more hidden layer(s) $[85,86]$. Interestingly, these neurons are not interlinked within the same layer but are linked with the other neurons of the other layers [85, 86]. During many training cycles to reduce error values, different techniques were used, changing the weight of each link [9-13]. To reduce the error, the cross-validation technique is used by dividing the input data into three subsets data as discussed in the previous work of the author [9-13]. In this case, it can be said that the network has learned the function of a particular goal. As the name of the algorithm suggests, errors are propagated back from the output node to the input node. ANN's chosen architecture describes the quantity of hidden layer(s) and the quantity of neuron(s) in each layer(s), as illustrated in Figure 6. Equation (7) describes the mathematical function of the artificial neuron as

$$
O=f\left(\sum x_{z} w_{z}+b\right)
$$

where $O$ value is predicted using $\mathrm{ANN}, x_{\mathrm{z}}$ represents assigned input values, $w_{z}$ corresponds to link values, and extraparametric values are represented by $b$.

As shown in Figure 6, the results of the activation are then transferred to the next layer. Then, based on available information, final selected weights are calculated. In the present and past studies, the authors used ANNs $[42,45,48,87,88]$ to estimate the load-bearing capacity of the materials and individual RC members [42, 45, 48, 87, 88]. In the current study, tanh and hyperbolic activation functions are used between input and intermediate layers, while hyperbolic functions have been used between intermediate and output layers. The inaccuracy occurring during the process can be counted using equation (8). Once ANN is trained, equation (8) is used to compare the results obtained with already known target values:

$$
E(w)=\frac{1}{2} \sum_{i}[T-O]^{2},
$$

where $T$ and $O$ are target predicted values, respectively.

3.1. Database ofSCS for ANNModelling. To predict punching strength of RC flat slabs (SCS), the database was comprised of 145 SCS samples, as shown in Figure 7. The data regarding critical parameters, i.e., column dimension, $c_{s}$, depth of the slab, $d_{s}$, shear span ratio, $a_{v s} / d$, longitudinal percentage steel ratio, $\rho_{l s}$, longitudinal steel yield strength, $f_{y l s}$, concrete compressive strength, $f_{c s}$, and ultimate load-carrying capacity, $V_{u s}$, is provided in Table 1. Out of 145 samples, $99 \%$ were failed in the shear manner and remaining in flexure. The histogram for critical parameters has been described in Figure 8(a). The figure described different parametric frequencies for certain sample values. It also defined limitations for ANN models that were to predict against limits of different parameters. The sensitivity analysis is carried out by using the correlation of the critical parameters as exhibited in Figure 8(b). 

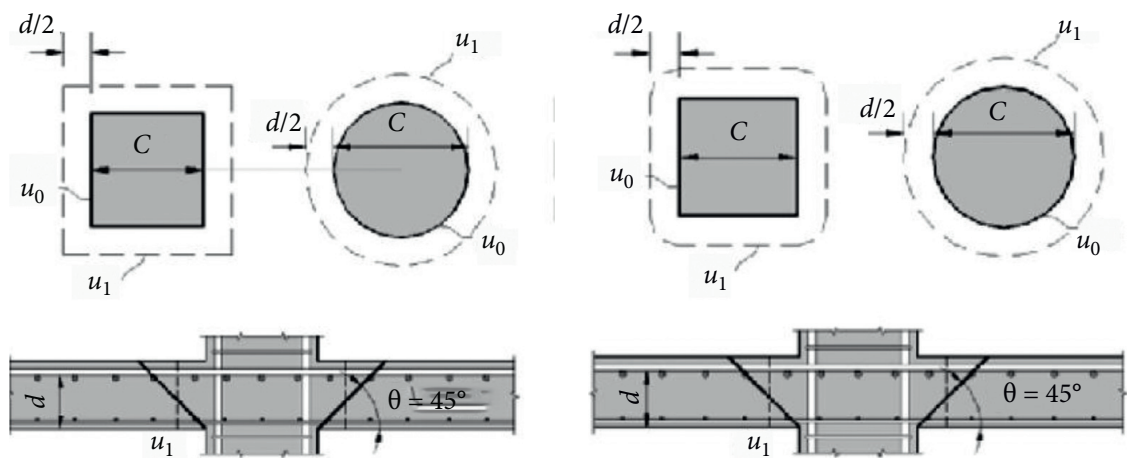

(a)

(b)

FIgURE 4: Important boundary for SCS. (a) ACI and (b) EC2 [2-4].

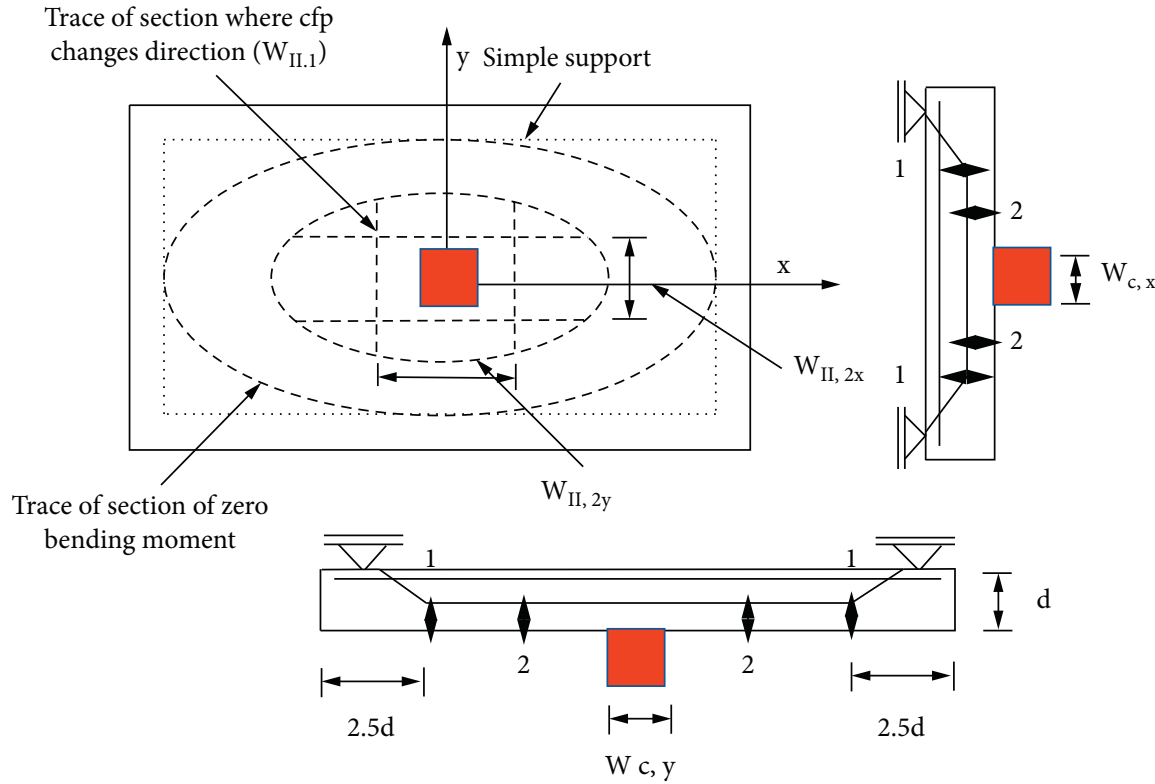

FIGURE 5: CFP assumption for the punching failure of SCS [6].

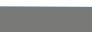

Free Forward Calculation (Input Signal)

INPUT LAYERS

HIDDEN LAYERS OUTPUT LAYERS

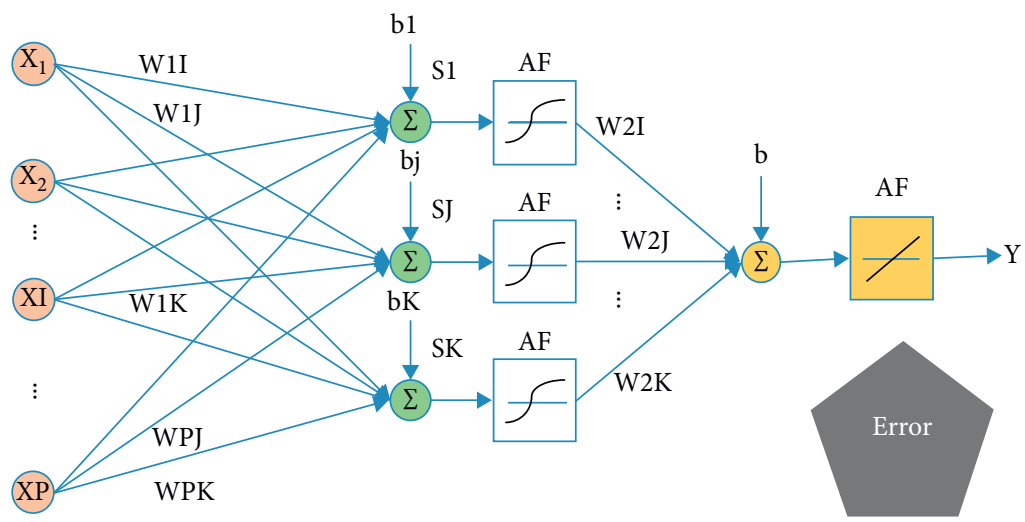

Back-Propagation (Error Signal)

FIGURE 6: ANN representation using the simplified mathematical function [42]. 

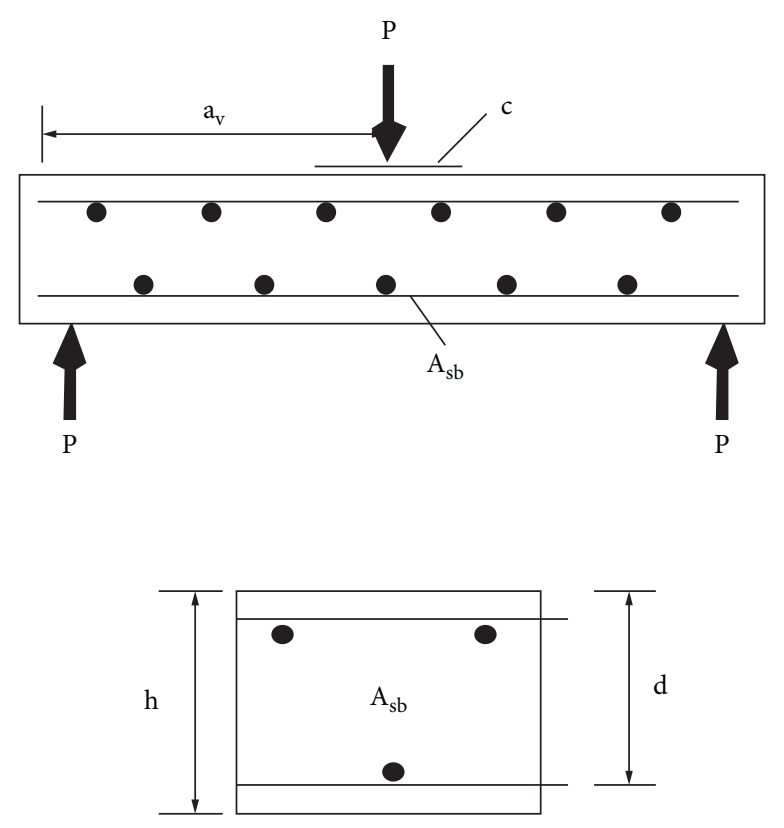

Cross section

Figure 7: Typical lab setup for SCS.

TABle 1: Parameters details in the database for SCS.

\begin{tabular}{lcccccccc}
\hline & $c_{s}(\mathrm{~mm})$ & $d_{s}(\mathrm{~mm})$ & $a_{v} / d$ & $\rho_{l s}(\%)$ & $f_{y l s}(\mathrm{MPa})$ & $f_{c s}(\mathrm{MPa})$ & $M_{f s}(\mathrm{kN}-\mathrm{mm})$ & $V_{u s}(\mathrm{kN})$ \\
\hline Min & 54 & 64 & 4.5 & 0.3 & 294 & 9.52 & 39000 \\
Max & 600 & 275 & 14.02 & 6.9 & 749 & 118.7 & 1951000 \\
Avg. & 206.34 & 122.32 & 7.81 & 1.31 & 496.88 & 41.3 & 252655 \\
St. dev & 87 & 44.82 & 2.4 & 0.89 & 117.68 & 24.85 & 292121 \\
COV & 0.42 & 0.37 & 0.31 & 0.68 & 0.24 & 0.6 & 458.7 \\
\hline
\end{tabular}

3.2. Preprocessing Phase. ANN training gets significantly affected by standard data points because regardless of the unit system followed, all the different inputs at this point become common among the same values [44, 45]. Therefore, by using equation (9), all the critical parameters used in this work are eventually normalized between 0.1 and 0.9 :

$$
X=\frac{\Delta X}{\Delta x} x+\left(X_{\max }-\frac{\Delta X}{\Delta x} x_{\max }\right)
$$

where $x$ is the current value, $X$ is the normalized/uniform value, and $\Delta$ is the difference of limits.

In the present case, the value of the $X_{\max }=0.9$ and $\Delta X=0.8$ are used against the new limits of 0.1 to 0.9 . Pearson's correlation coefficient $(R)$, as given by equation (10), was used to make different combinations of parameters $[42,45,48,87,88]$. Importance of the output parameter is determined based on difference of $|R|$ values for input and output parameters:

$$
R=\frac{\sum_{i=1}^{n}\left[\left(T_{i}-\bar{T}\right)\left(O_{i}-\bar{O}\right)\right]}{\sqrt{\sum_{i=1}^{n}\left(T_{i}-\bar{T}\right)^{2} \cdot \sum_{i=1}^{n}\left(O_{i}-\bar{O}\right)^{2}}} .
$$

For the modeling and training of ANN models, the author used the same procedures and guidelines as suggested in his own work $[42,45,48,87,88]$. For this purpose, a total of 7 different ANN models (as described in Table 2) with different combinations of the designed parameters for the SCS were used. The choice of these critical input parameters was built on the physical models i.e., CDCs which describe the machines under the SCS at ULR.

3.3. Optimized ANN Model. A multilayer ANN model was used to carry out the main features for the learning process of ANN. The MLFNN method of Levenberg-Marquardt was used by the authors for coding of the ANN model in the MATLAB environment [46]. The main ANN architecture as used by the authors was obtained from previous work of authors [11,43]. The optimized ANN model was selected based on (i) error calculation using Pearson's correlation for coefficient $(R)$, (ii) mean absolute error (MAE), and (iii) mean squared error (MSE) [47, 48] which are analytically expressed by equations (10), (12) and (13), respectively:

$$
\begin{aligned}
\text { MSE } & =\frac{\sum_{i=1}^{n}\left(T_{i}-O_{i}\right)^{2}}{n}, \\
\text { MAE } & =\frac{\sum_{i=1}^{n}\left|T_{i}-O_{i}\right|}{n},
\end{aligned}
$$



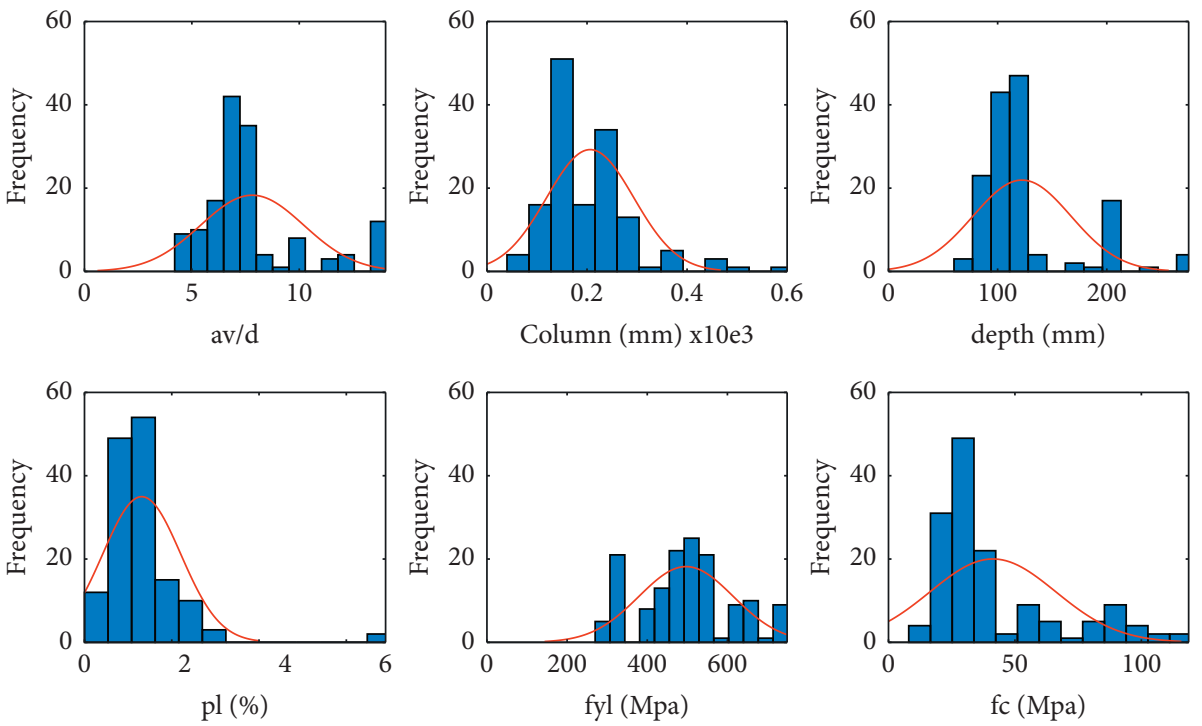

(a)

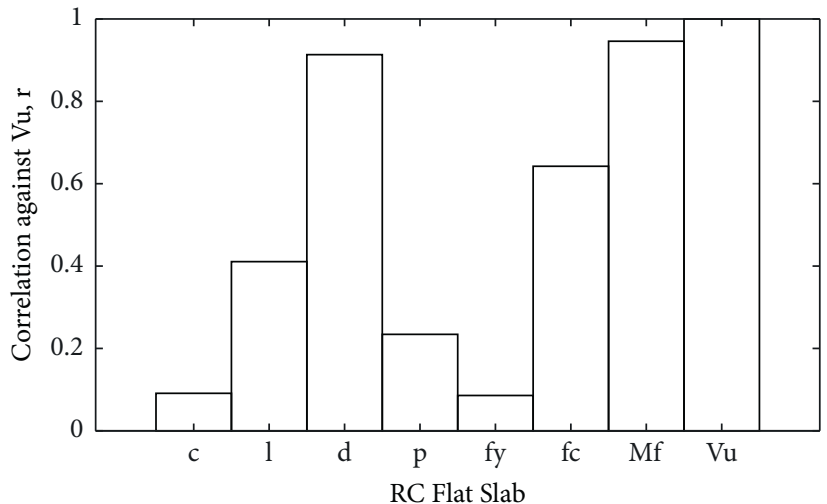

(b)

Figure 8: (a) Histogram for critical parameters and (b) correlation of critical parameters for reinforced concrete flat slab.

TABLE 2: Combination of parameters of ANN models for SCS.

\begin{tabular}{|c|c|c|c|c|c|c|c|}
\hline Sr. no. & ANN & Combination of parameters & Inputs & L1-2 & A L3-4 & Hidden & Output \\
\hline 1 & $\mathrm{SCS}=1$ & $\rho_{l s}, f_{y l s}, f_{c s}, c_{s}, d_{s}$, and $a_{v s} / d_{s}$ & 06 & SDF & THF & 12,12 & $V_{u}, 1$ \\
\hline 2 & $\mathrm{SCS}=2$ & $M_{f s}, f_{c}, c_{s}, d_{s}$, and $a_{v s} / d_{s}$ & 05 & SDF & THF & 10,10 & $V_{u}, 1$ \\
\hline 3 & $\mathrm{SCS}=3$ & $M_{f s} / f_{c s} b d_{s}^{2,} c_{s} / d_{s}$, and $a_{v s} / d_{s}$ & 03 & SDF & THF & 6,6 & $V_{u}, 1$ \\
\hline 4 & $\mathrm{SCS}=4$ & $\rho_{l s}, f_{c s} / f_{y l s}, c_{s} / d_{s}$, and $a_{v s} / d_{s}$ & 04 & SDF & THF & 8,8 & $V_{u}, 1$ \\
\hline 5 & $\mathrm{SCS}=5$ & $M_{f_{s}} / b d_{s}^{2}, f_{c s}, d_{s}$, and $a_{v s} / d_{s}$ & 04 & SDF & THF & 8,8 & $V_{u}, 1$ \\
\hline 6 & $\mathrm{SCS}=6$ & $M_{f_{s}} / f_{c s} b d_{s}^{2,} d_{s}, c_{s} / d_{s}$, and $a_{v s} / d_{s}$ & 04 & SDF & THF & 8,8 & $V_{u}, 1$ \\
\hline 7 & $\mathrm{SCS}=7$ & $M_{f_{s}} / f_{c s} b d_{s}^{2}, f_{s c} d_{s}, c_{s} / d_{s}$, and $a_{v s} / d_{s}$ & 05 & SDF & THF & 10,10 & $V_{u}, 1$ \\
\hline
\end{tabular}

$\mathrm{SDF}=$ sigmoid; $\mathrm{THF}=$ tanghn

where $\mathrm{O} i$ are the given target results, $\mathrm{Ti}$ are predicted results from ANN, and the number of all samples in the databank is represented by $n$ [9-13].

Optimized ANN model is the one with lowest MSE and MAE values and highest $R$ values [9-13].

Based on Figures 9 and 10, the SCS $=4\left(\rho_{l s}, f_{c s} / f_{y l s}, c_{s} / d_{s}\right.$, and $\left.a_{v s} / d_{s}\right)$ is the best model fulfilling abovementioned criteria. However, like every other ANN model, this model was also used between the statistical information as discussed in Table 1. As the future work, more samples will be included from the available database to cover all the realistic sizes and material strength of the flat slab.

\section{Comparative Studies of Flat Slab}

In this section, the ANN-based predicted models, as discussed above, have been compared with the CFP method $[52,53]$ and with CDCs $[1,2]$, and the resulting data have been presented in Figures 11-13. Figure 11 presented the prediction results as the ANN, CFP, and CDCs against the 

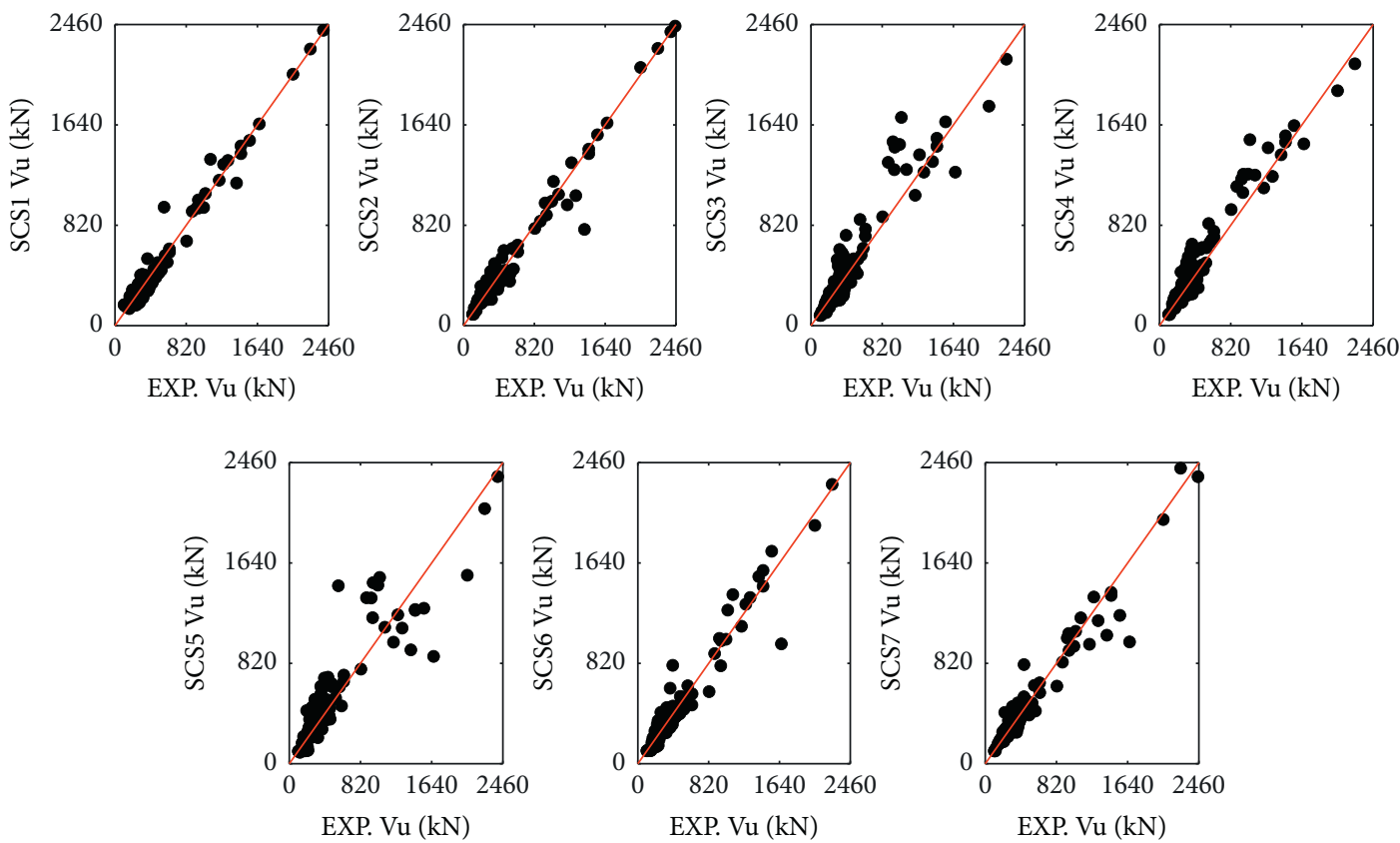

FIgURE 9: ANN models' predictions for the SCS.
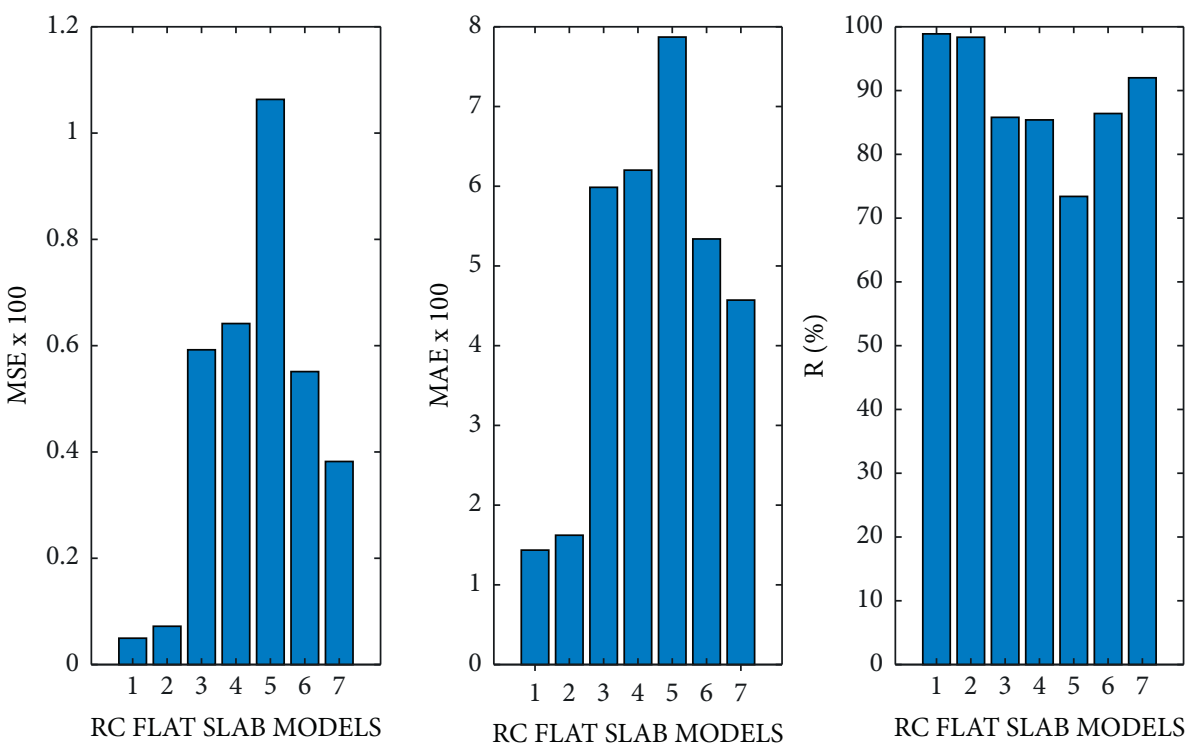

Figure 10: ANN models' error for the SCS.

experimental values (EXP). The results exhibited that, as compared with CDCs, the ANN and CFP are closer to the EXP results.

Figure 12 illustrates the normal distribution (ND) of the $V_{E X P} / V_{P R E D}$ ratios, for ANN (calculated as $V_{E X P} / V_{A N N}$ ) presenting the least standard deviation of 1.05 and was followed by CFP. After that, GD curves for CDCs (i.e., EC2 and $\mathrm{ACI}$ ) have a wide range from 0 to 2 on the $x$-axis and a peak value smaller than 1.0 on the $y$-axis.

Overestimated and underestimated values for ULR have been presented in Figure 13. As observed before, the results obtained by using CDCs were lower than the provided ones, and $90 \%$ results against nonconventional models were ranged into the accurate region i.e.; between 0.755 and 1.255. The values obtained by other physical models were mostly underestimated compared to the ones obtained using ANN and CFP methods.

\section{Parametric Studies of Flat Slab}

This part is very important as it highlights the effect of the parametric studies against the prediction of CDCs (ACI and EC2) [2, 3], the CFP method [6], and the selected ANN model. The parametric investigation is done against the ratio of $V_{E X P} / V_{P R E D}$ for necessary design parameters only, i.e., parameters considered are column dimension, $c_{s}$, depth of 

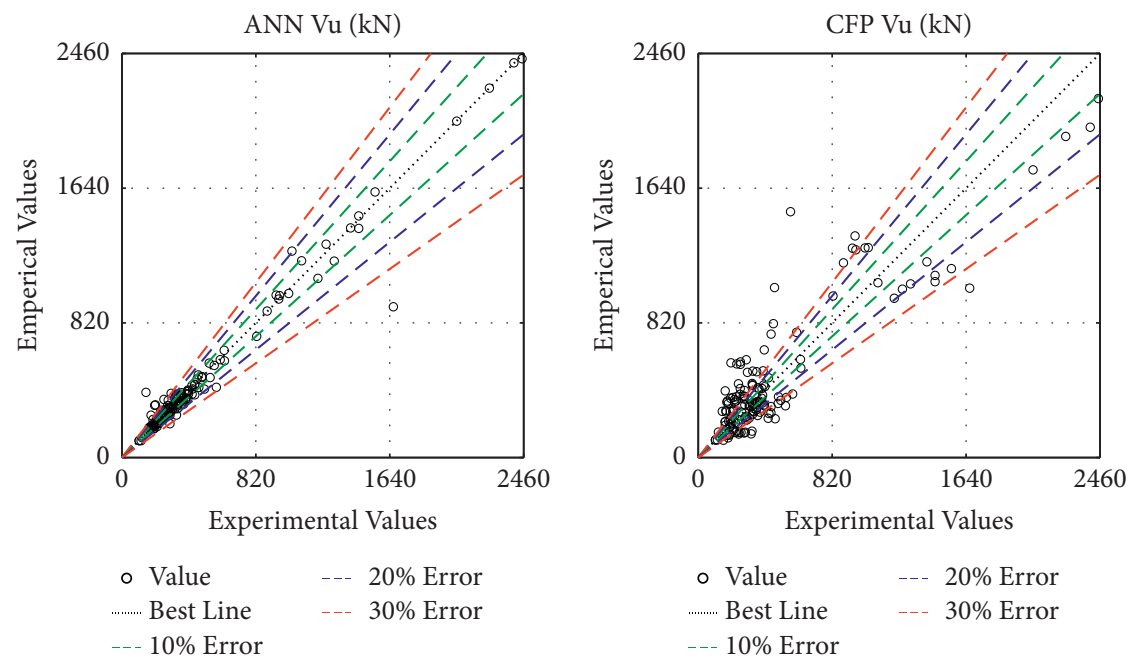
- Value
-- $20 \%$ Error
........ Best Line
-.- $30 \%$ Error
--- $10 \%$ Error
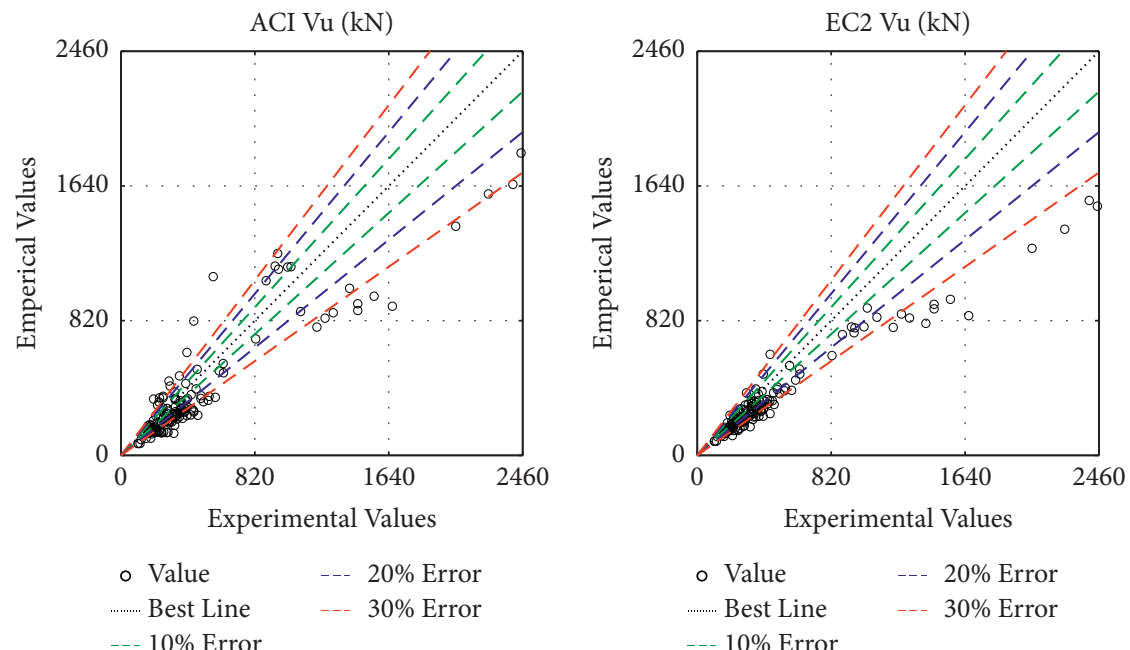

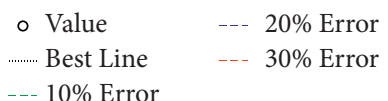

Figure 11: Comparison of predictions from ANN, CFP, ACI, and EC2 for SCS.

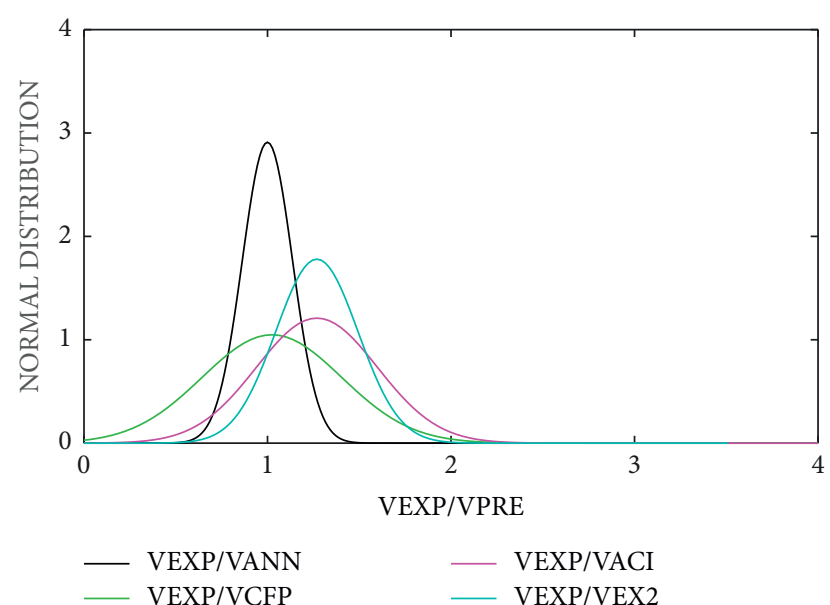

FIgURE 12: ND or GD of ratios for the case of SCS.

the slab, $d_{s}$, shear span ratio, $a_{v s} / d_{s}$, longitudinal percentage steel ratio, $\rho_{l s}$, longitudinal steel yield strength, $f_{y l s}$, concrete compressive strength, $f_{c s}$, and ultimate load-carrying capacity, $V_{u s}$

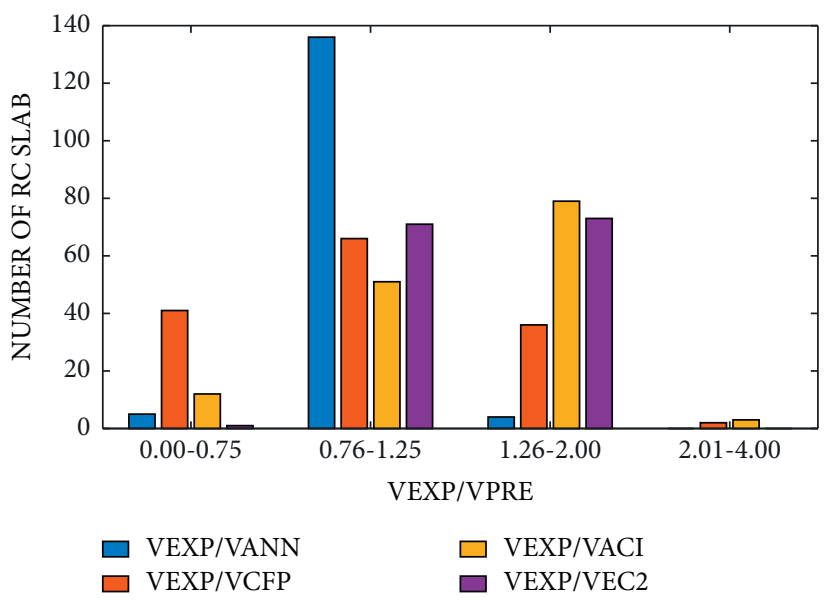

FIgURE 13: Range limits of ratios for the SCS.

5.1. Effective Depth $\left(d_{s}\right)$ and Shear-to-Depth against Ratios $\left(a_{v s} / d_{s}\right)$. The two most important geometric parameters for predicting the response of punching failure of the SCS are depth $\left(d_{s}\right)$ and shear-to-depth against ratios $\left(a_{v s} / d_{s}\right)$, as 
illustrated in Figures 14 and 15, respectively, for the case of the SCS. It is worth noting that, during the comparative study of the effect of $\left(d_{s}\right)$ and $\left(a_{v s} / d_{s}\right)$ against the suggested ratio of $V_{E X P} / V_{P R E D}$, the results of ANN ( $\left.V_{A N N}\right)$ are close to the experimental ratio, as illustrated in Figures 14 and 15. The scatter of the point for the other ratio (CDCs and CFP) $V_{E X P} / V_{A N N}$ are far away from the line of unity. Furthermore, for the samples having a value between $75 \mathrm{~mm}<d<135 \mathrm{~mm}$ and for the $5<a_{v} / d<10$ showed the extensive deviation from the line of unity for the ratio $V_{E X P} / V_{P R E D}$, as illustrated in Figures 14 and 15. Therefore, there is an urgent need to revise the CDC especially for the mentioned limits of the depth (d) and shear-to-depth against ratios (av/d).

\subsection{Compressive Strength $\left(f_{c}\right)$ and Longitudinal Steel Ratio $\rho_{l}$} (\%). The two most important material parameters for predicting the response of punching failure of SCS are compressive strength $\left(f_{c}\right)$ and longitudinal steel ratio $\rho_{l}(\%)$, as illustrated in Figures 16 and 17, respectively for the case of the SCS. It is worth noting to note that, during the comparative study of the effect of $\left(f_{c}\right)$ and $\rho_{l}(\%)$ against the suggested ratio of $V_{E X P} / V_{P R E D}$, the results of ANN ( $\left.V_{A N N}\right)$ are close to the experimental ratio and the line of unity, as illustrated in Figures 16 and 17. The scatter of the points for other ratios (CDCs and the CFP) $V_{E X P} / V_{A N N}$ are far away from the line of unity. Furthermore, the samples having a value between $20 \mathrm{MPa}<f_{c}<40 \mathrm{MPa}$ and for $1.5 \%<\rho_{l}<2.5 \%$ showed the extensive deviation from the line of unity for the ratio $V_{E X P} / V_{P R E D}$, as illustrated in Figures 16 and 17. Therefore, there is an urgent need to revise the CDC especially for the mentioned limits of depth, compressive strength $\left(f_{c}\right)$, and longitudinal steel ratio $\rho_{l}(\%)$

\section{Assessment of RC Flat Slab through NLFEA}

Mostly the smeared crack and concrete-damaged plasticity (CDP) model are used for studying the nonlinear behavior of concrete in ABAQUS. In the smeared crack concrete modeling as the failure, the cracking phenomenon starts appearing at the failure surface either in biaxial tension or at the tension and compression region [89]. This model is used where concrete cracking occurs due to tension and crushing failure occurs due to compression. When a uniaxial loading testing of concrete is done in tension, it behaves as an elastic material up to $7.5 \%-11 \%$ of final compressive stress after which the specimen starts to crack. This crack formation and propagation occur so quickly that it is very challenging to observe the actual response. As the loss of elastic stiffness gives rise to crack opening and crack is considered as damage to the structure, the model also takes the cracking phenomenon as damage. It is also supposed that there is no permanent sign of the strain associated with the cracking phenomenon which is why crack will be considered as completely close when stresses across the crack become compressive [90].

6.1. Concrete Damage Plasticity (CDP) Model. In the inelastic range, the material behavior of concrete is defined by using the concrete-damaged plasticity model (CDPM) in Abaqus.
This model was developed by Lee and Han in 1998. Concrete behavior under low confining pressure is brittle, and using this model, its failure mechanism is based upon stress and inelastic strain [91]. $K_{c}$ is a ratio of distances between the hydrostatic axis to the corresponding compression and tension meridians. In a deviatory cross section, its value is always higher than 0.5 , and when it turns into 1 , the failure surface becomes a circle in the deviatory cross section (Drucker-Prager). Similarly, eccentricity is a ratio of tensile strength to compressive strength and according to the Drucker-Prager strength hypothesis, and when eccentricity is zero, the surface becomes a straight line in a meridional plane. To describe the state of the material in the CDP model, another parameter is stress ratio $\sigma_{b o} / \sigma_{c o}$ which may be defined as the ratio of biaxial to uniaxial strength. The dilation angle also affects the performance of concrete under compound stress, which may be defined as the failure of concrete [92]. The default values of the above-discussed parameters are given in Table 3 .

To study the nonlinear behavior of slab elements, wellknown commercial software ABAQUS was used. First of all, the full-scale sample of the slab was analyzed but it was taking too much time to complete the analysis. To reduce the analysis time, a quarter slab sample was generated and boundary condition was defined to fulfill the continuity condition, as shown in Figure 6. This quarter slab was calibrated against the geometric and material parameters, such as dilation angle, mesh size, viscosity, eccentricity, a ratio of uniaxial stress to biaxial stress, and different element types of steel and concrete. By using the load-displacement technique, the specimen was analyzed and the result was extracted to plot the load-deflection curve. After calibrating the control model, this calibrated model was employed for the remaining specimens and load-deflection curves were plotted with help of MATLAB.

The stiffness degradation of concrete on the strainsoftening portion of the stress-strain curve is defined by the two different variables, $d t$ and $d c$, whose values may vary from zero to one. Zero shows that there is no damage to the material, and one shows a total loss of strength [93]. $E_{\mathrm{o}}$ is the elastic stiffness of the material initially, and $\varepsilon_{c}^{\sim i n}, \varepsilon_{t}^{\sim i n}, \varepsilon_{c}^{\sim p l}$, and $\varepsilon_{t}^{\sim p l}$ are compressive inelastic strain, tensile inelastic strain, compressive plastic strain, and tensile plastic strain, respectively. The relationship between stress and strain under uniaxial tension and compression is considered as given in following equations:

$$
\begin{gathered}
\sigma_{t}=\left(1-d_{t}\right) E_{o}\left(\varepsilon_{t}^{\sim i n}-\varepsilon_{t}^{\sim p l}\right), \\
\sigma_{c}=\left(1-d_{c}\right) E_{o}\left(\varepsilon_{c}^{\sim i n}-\varepsilon_{c}^{\sim p l}\right) .
\end{gathered}
$$

The strain-softening behaviour of the cracked concrete can be simulated using tension stiffening. Thus, it is required to define the tension stiffening behaviour in the DPMO model. In ABAQUS, we can specify the tension stiffening by the post-failure stress-strain relationship of the concrete or by applying a fracture energy cracking criterion [93].

The variable $\varepsilon_{t}^{\sim p l}$ is associated with crushing and microcracking process within the concrete, and it represents tensile or compressive equivalent plastic strains. Important 

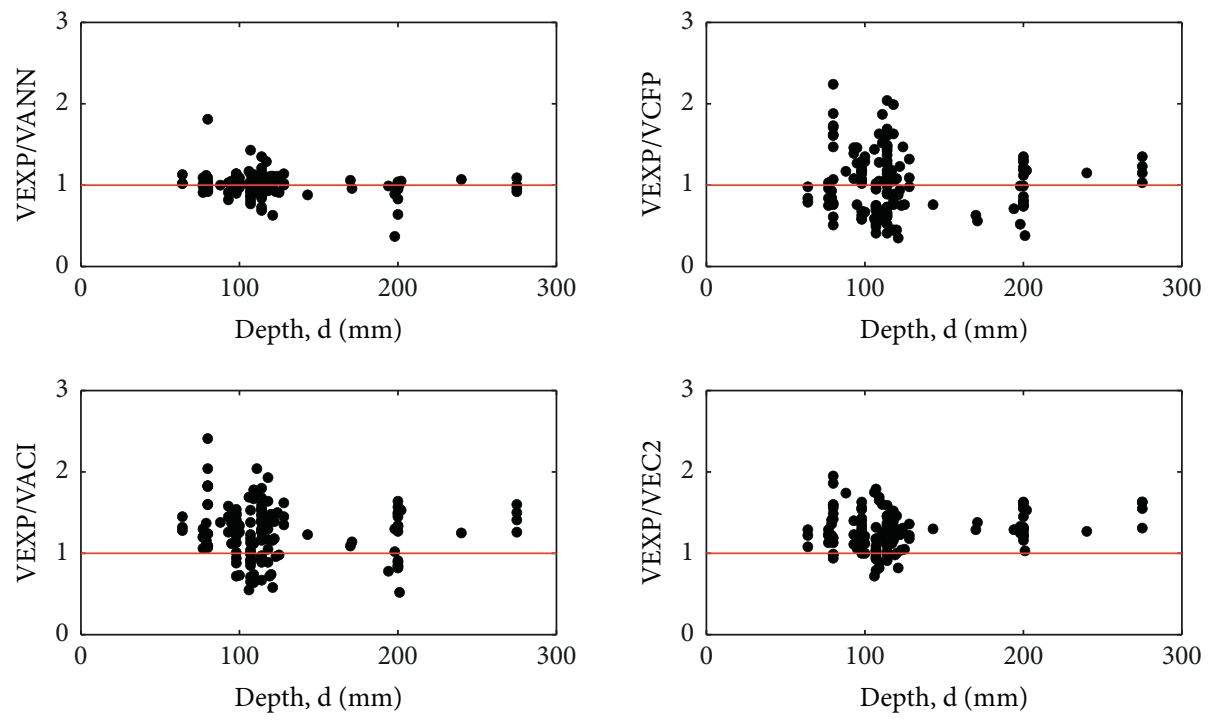

FIgURE 14: Ratio against depth, $d$ (mm), for SCS.
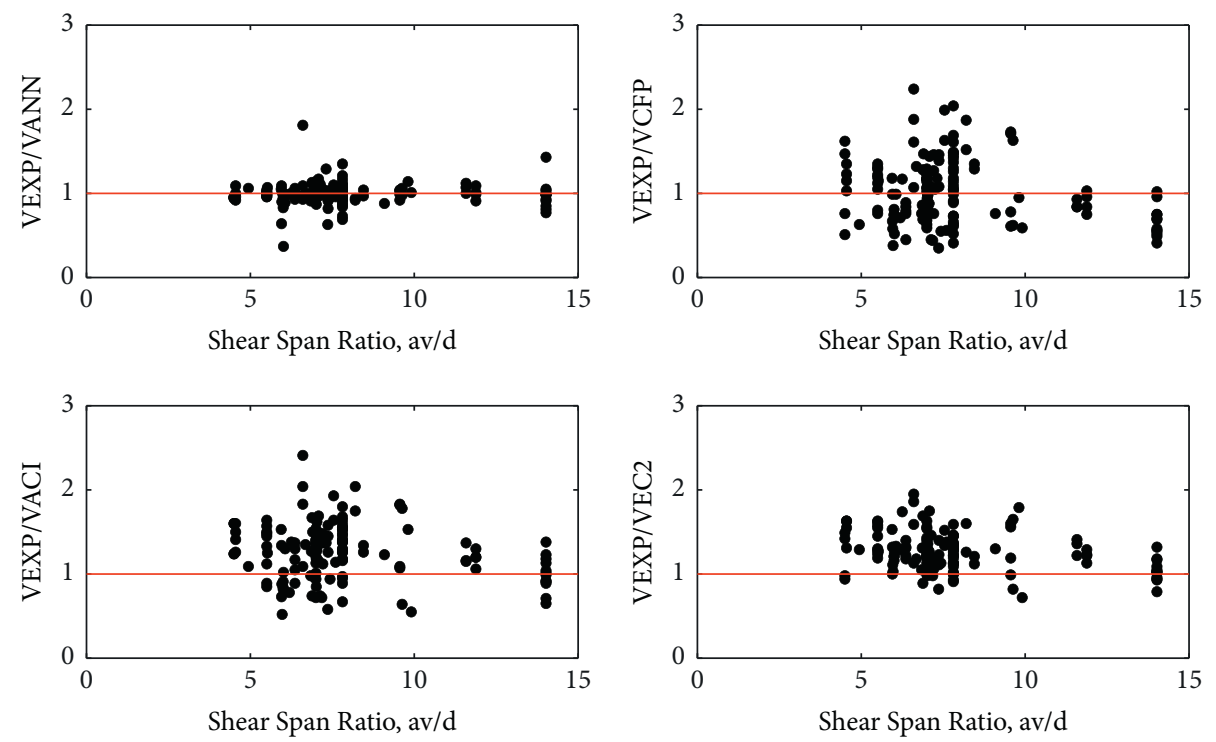

Figure 15: Ratio against av/d (ratio) for SCS.

parameters that need to be defined in the plastic behaviour of concrete using CDPM are the dilation angle $\psi_{s}$, viscosity parameter $\mathbf{v}_{\mathbf{s}}$, uniaxial stress to biaxial stress ratio $\left(\sigma_{b o} / \sigma_{c o}\right)$, load eccentricity $(\varepsilon s)$, and shape factor of the yielding surface $\left(K_{c}\right)$, as discussed in Table 4 . The accurate simulation of the tensile behaviour of concrete for the flexural members is very important to achieve accurate results. This model presents a stress-strain model at postfailure conditions of concrete by taking into consideration the tension stiffening behaviour, strain-softening behaviour, and interactions between the concrete and steel bars, as illustrated in Figure 18.

6.2. Simulations of Steel Reinforcing Bars. In the FEA, steel bars were taken as the elastoplastic material and their interaction with concrete was defined as an embedded region.
Similarly, concrete was taken as a host region. A perfect bond between steel and concrete was assumed. Material properties of steel bars used in the present work are yield strength of $420 \mathrm{MPa}$, Poisson's ratio of 0.3 , and modulus of elasticity as $200 \mathrm{GPa}$, as illustrated in Figure 19. To simulate the steel bars, a truss element having two nodes and three translations at every node (T3D2) was considered.

For the validation purposes of ANN, selected cases of RC flat slab from the database are modeled in ABAQUS [93], and the information of these cases is summarized in Table 3. Figure 20 described the comparative study of CDCs, ANN, CFP, and ABAQUS [93].

Figure 21(a) illustrates that ABAQUS load-deflection (LD) curves (shown in dotted lines) are in reasonable relation with the experimental curves (shown in solid lines). Figure 21(b) explains the transfer of principal stress, i.e., S33, 

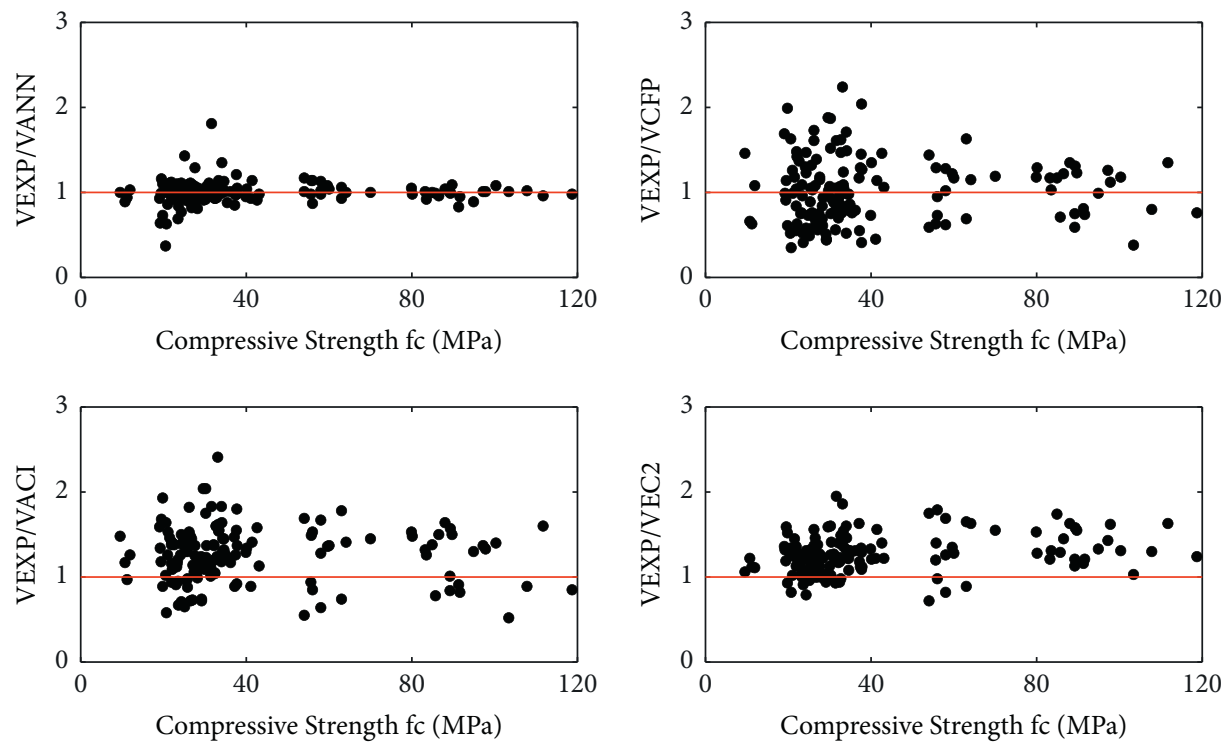

FIGURE 16: Ratio against compressive strength $f_{c}(\mathrm{MPa})$ for SCS.
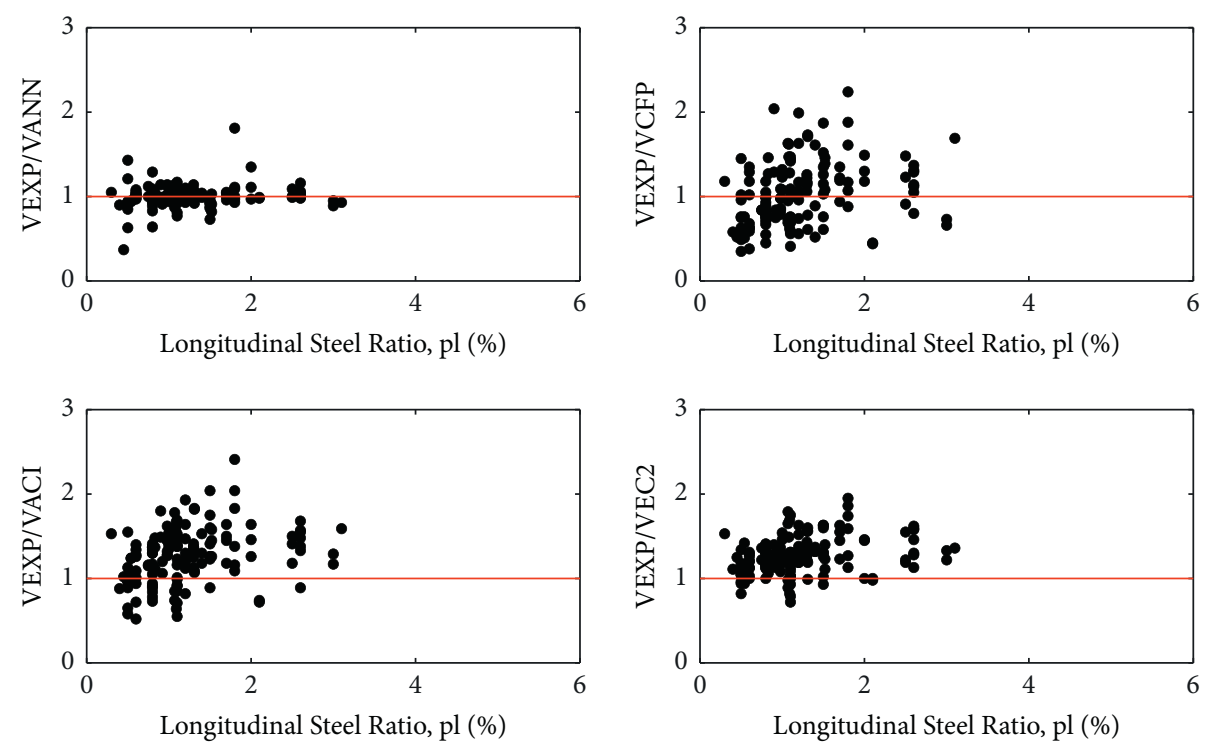

FIgURE 17: Ratio against longitudinal ratio $\rho_{l}$ (\%) for SCS.

TABLe 3: Selected samples for SCS.

\begin{tabular}{lcccccc}
\hline Source & Name & $\begin{array}{c}d_{\mathrm{s}} \\
(\mathrm{mm})\end{array}$ & $\begin{array}{c}c_{\mathrm{s}} \\
(\mathrm{mm})\end{array}$ & $\mathrm{a}_{\mathrm{vs}} / d_{\mathrm{s}}$ & $\begin{array}{c}f_{c s} \\
(\mathrm{MPa})\end{array}$ & $\begin{array}{c}f_{y s} \\
(\mathrm{MPa})\end{array}$ \\
\hline Kotsovos et al. [6] & $\mathrm{S} 1$ & 205 & 255 & 6.2 & 24.25 & $\begin{array}{c}\rho_{l s} \\
(\%)\end{array}$ \\
Kotsovos et al. [6] & $\mathrm{S} 3$ & 205 & 255 & 6.2 & 24.25 & 655 \\
Caldentey et al. [94] & $\mathrm{C} 1$ & 255 & 455 & 5.6 & 33.95 & 665 \\
\hline
\end{tabular}


TABLE 4: CDP calibration summary.

\begin{tabular}{lccc}
\hline Sr. no. & Descriptions of parameter & Ranges of values & Optimized value \\
\hline 1 & Dilation angle, $\psi_{\mathbf{s}}$ & $15,25,35,45,55$ & $\mathbf{3 5}$ \\
2 & Eccentricity, $\boldsymbol{\varepsilon s}$ & $0.0015,0.055,0.15,0.25,0.45$ & $\mathbf{0 . 1 5}$ \\
3 & Stress ratio, $\sigma_{\mathbf{b} 0} / \sigma_{\mathbf{c o}}$ & 1.165 & $\mathbf{1 . 1 6 5}$ \\
4 & Shape factor, $\mathbf{K}_{\mathbf{c}}$ & $0.15,0.35,0.65,0.95,1.25$ & $\mathbf{0 . 6 5}$ \\
5 & Viscosity parameter, $\mathbf{v}_{\mathbf{s}}$ & $0.0015,0.0025,0.0035,0.0045,0.0055$ & $\mathbf{0 . 0 0 3 5}$ \\
6 & Mesh size $(\mathrm{mm})$ & $15,25,55,95,115$ & $\mathbf{5 5}$ \\
\hline
\end{tabular}

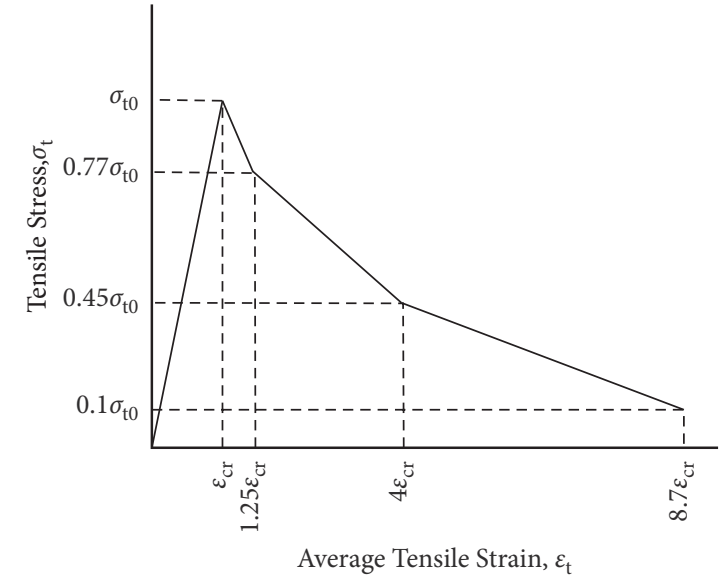

(a)

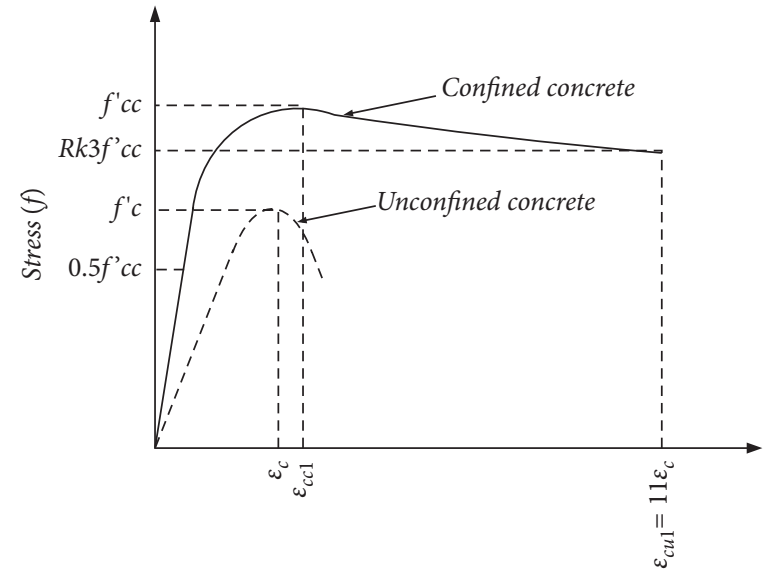

$\operatorname{Strain}(\varepsilon)$

(b)

FIgURE 18: Behaviour of the concrete (a) in tension and (b) compression under the uniaxial loading [93].

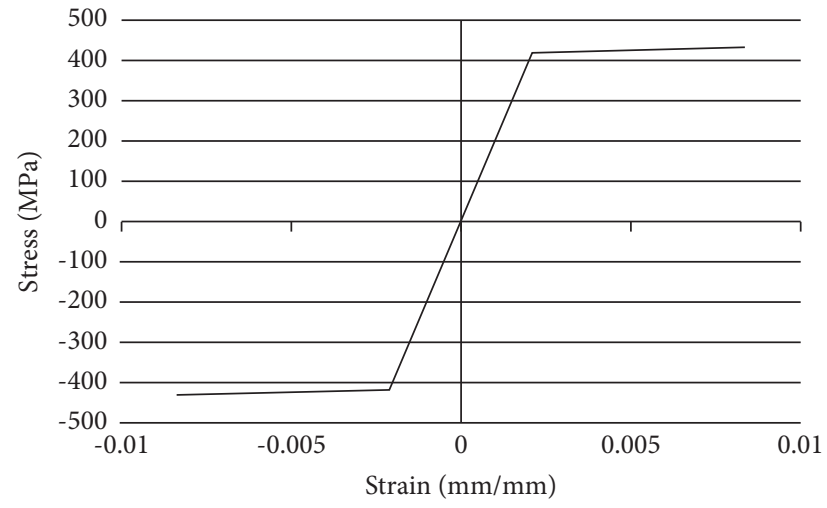

Figure 19: Concrete stress-strain used in CDPM [93].

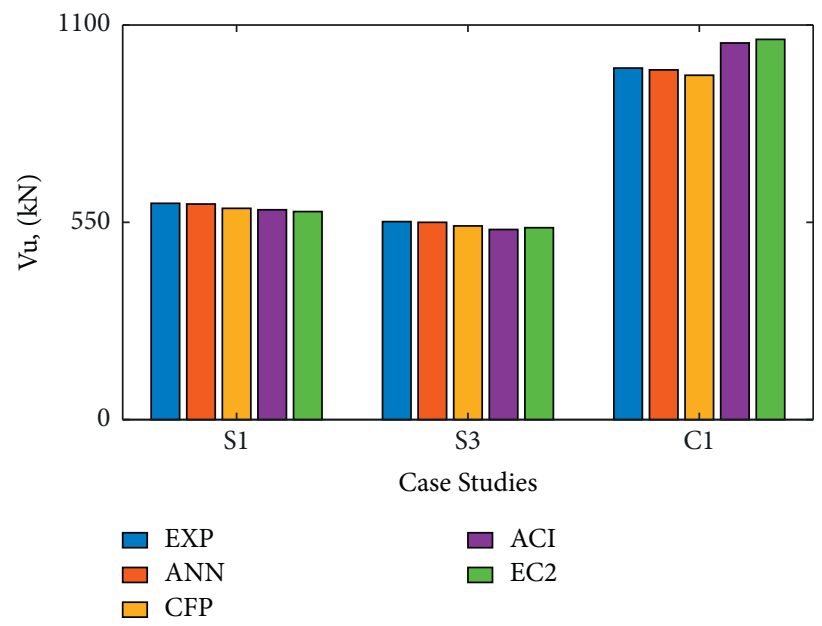

FIGURE 20: Validation of ANN prediction through counterparts. 

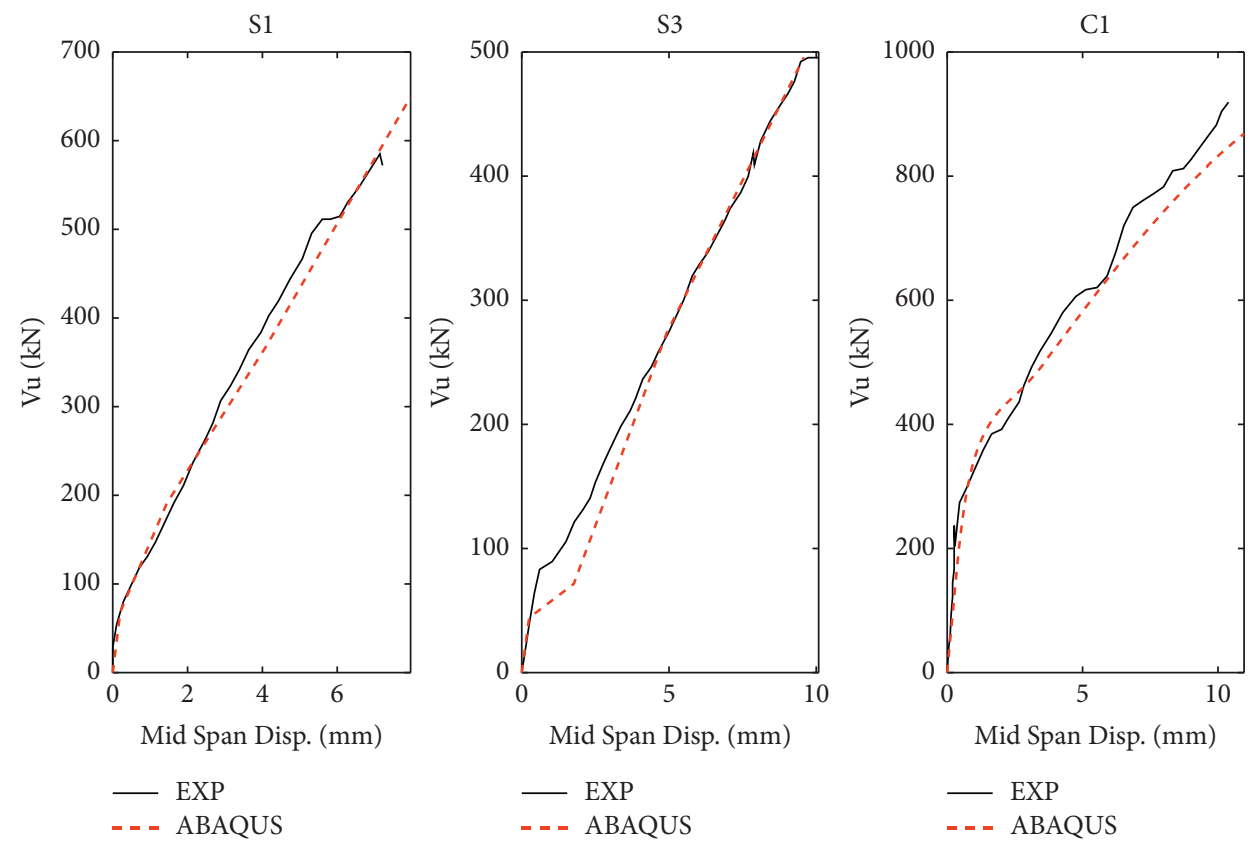

(a)
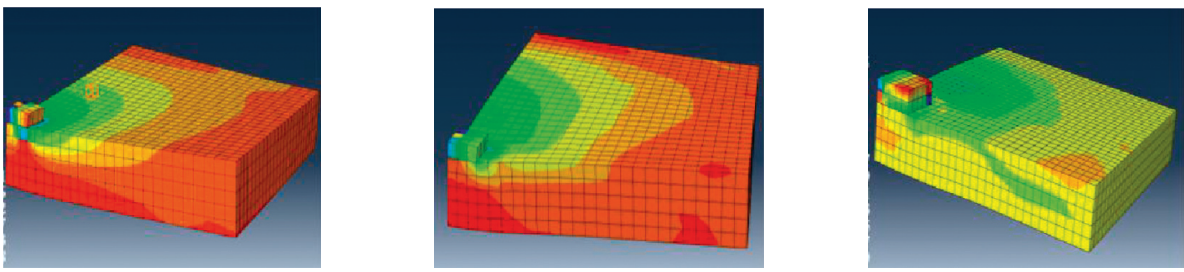

(b)
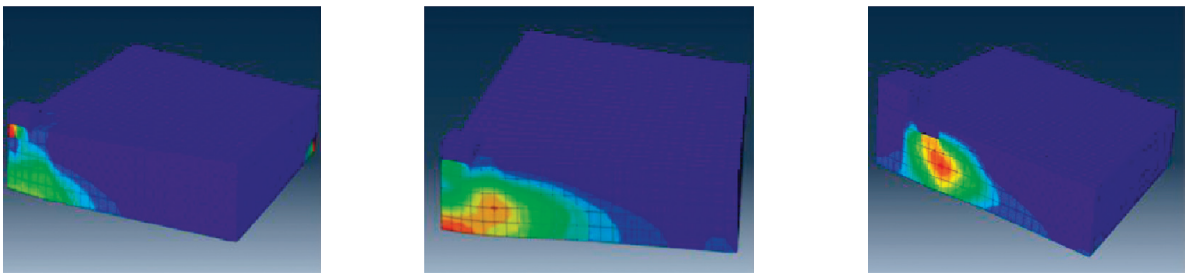

(c)
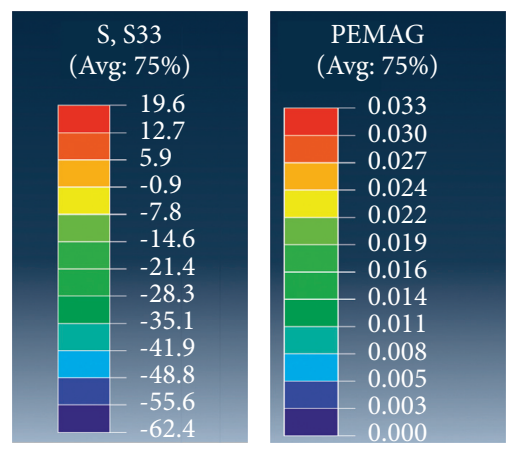

(d)

Figure 21: (a) LD curve, (b) S33, (c) PEMAG, and (d) LEGEND for SCS. 
which is similar to the CFP arch-like frame, as shown in Figure 5, and Figure 21(c) illustrates the plastic strain magnitude (i.e., PEMAG) along the "critical lengths."

\section{Conclusions}

In the current study, capability of ANN modeling is described for RC flat slab with the simply-supported condition under punching load, while the parameters considered are column dimension, $c_{s}$, depth of the slab, $d_{s}$, shear span ratio, $a_{v s} / d_{s}$, longitudinal percentage steel ratio, $\rho_{l s}$, yield strength of longitudinal steel, $f_{y l s}$, compressive strength of concrete, $f_{c s}$, and ultimate load-carrying capacity, $V_{\text {us. }}$. Following are the main conclusions of the present work:

(1) As a result of the comparative study, it has been revealed that nonconventional ANN models predicted the experimental values well compared to conventional models i.e., CDCs and CFP. Similar results have been provided by other researchers using different databases [11, 40-48]. Therefore, behavior of reinforced concrete members with different geometry and loading conditions can better be estimated using ANN models.

(2) After training ANNs using a certain database, corresponding structural response can accurately be predicted at ULR irrespective of material behavior and response. From the comparative study, it was revealed that ultimate response of $\mathrm{RC}$ members as predicted by ANN models was quite close to the one obtained from EC-2 and CFP and accurate compared to the one obtained from ACI Code.

(3) Among the different ANNs proposed, the optimized model was selected based on the $R$ value. For optimized ANN, the $R$ value was found to be $98 \%$ and SCS as $4\left(c / d, a_{v} / d, \rho_{l}\right.$, and $\left.f_{c} / f_{y}\right)$.

(4) The estimation obtained from ABAQUS (e.g., NLFEA) of selected case studies shows positive consensus with the experimental results and values provided by ANN. In addition, the numerical predictions obtained seem to support the fact that basic equipment of the RC flat slab specimens investigated is consistent with the visual model adopted by the CFP method.

\section{Data Availability}

The data used to support the findings of the study are available from the corresponding author upon request.

\section{Conflicts of Interest}

The authors declare that they have no conflicts of interest.

\section{References}

[1] S. Hentschel, "A neural network approach for predicting the structural behavior of concrete slabs," Master Thesis, Faculty of Engineering and Applied Science, Memorial University of Newfoundlan, St. John's, CA, USA, 1997.

[2] EC2, Eurocode 2: Design of Concrete Structures - Part 1-1: General Rules and Rules for Buildings, in EN 1992-1-1, Management Centre: Avenue Marnix 17, B-1000, Brussels, Belgium, 2004.

[3] ACI, Building Code Requirements for Structural Concrete (ACI 318-14) and Commentary, in Aci-318-14, pp. 1-471, American Concrete Institute 38800 Country Club Drive, Farmington Hills, MI 48331, USA, 2014.

[4] P. V. P. Sacramento, M. P. Ferreira, D. R. C. Oliveira, and G. S. S. A. Melo, "Punching strength of reinforced concrete flat slabs without shear reinforcement," Revista IBRACON de Estruturas e Materiais, vol. 5, no. 5, pp. 659-691, 2012.

[5] J. G. M. Wood, "Pipers row car park, wolverhampton," in Quantitative Study of the Causes of the Partial Collapse on 20th MarchHSE Publication, London, UK, 1997.

[6] M. D. Kotsovos, Compressive Force-Path Method, Springer, Berlin, Germany, 2014.

[7] D. Anderson and G. McNeill, Artificial Neural Networks Technology, pp. 1-83, Kaman Sciences Corporation, New York, NY, USA, 1992.

[8] I. A. Basheer and M. Hajmeer, "Artificial neural networks: fundamentals, computing, design, and application," Journal of Microbiological Methods, vol. 43, no. 1, pp. 3-31, 2000.

[9] M. Y. Rafiq, G. Bugmann, and D. J. Easterbrook, "Neural network design for engineering applications," Computers \& Structures, vol. 79, no. 17, pp. 1541-1552, 2001.

[10] H. Basarir, M. Elchalakani, and A. Karrech, "The prediction of ultimate pure bending moment of concrete-filled steel tubes by adaptive neuro-fuzzy inference system (ANFIS)," Neural Computing \& Applications, vol. 31, no. 2, pp. 1239-1252, 2019.

[11] S. Ganguly, A. Ahmed, and F. Wang, "Optimised building energy and indoor microclimatic predictions using knowledge-based system identification in a historical art gallery," Neural Computing \& Applications, vol. 32, no. 8, pp. 33493366, 2019.

[12] L. Schueremans and D. Van Gemert, "Assessing the safety of existing structures: reliability based assessment framework, examples and application," Journal of Civil Engineering and Management, vol. 10, no. 2, pp. 131-141, 2004.

[13] M. Mehrjoo, N. Khaji, H. Moharrami, and A. Bahreininejad, "Damage detection of truss bridge joints using artificial neural networks," Expert Systems with Applications, vol. 35, no. 3, pp. 1122-1131, 2008.

[14] M. P. Gonzalez and J. L. Zapico, "Seismic damage identification in buildings using neural networks and modal data," Computers \& Structures, vol. 86, no. 3-5, pp. 416-426, 2008.

[15] C. C. Chang, T. Y. P. Chang, Y. G. Xu, and M. L. Wang, "Structural damage detection using an iterative neural network," Journal of Intelligent Material Systems and Structures, vol. 11, no. 1, pp. 32-42, 2000.

[16] M. Shariati, A. Shariati, N. H. Ramli Sulong, M. Suhatril, and M. M. Arabnejad Khanouki, "Fatigue energy dissipation and failure analysis of channel shear connector embedded in the lightweight aggregate concrete in composite bridge girders," in Proceedings of the 5th International Conference on Engineering Failure Analysis, ICEFA, Hague, Netherlands, July 2012.

[17] M. Shariati, N. H. Ramli Sulong, M. Suhatril, A. Shariati, M. M. Arabnejad Khanouki, and H. Sinaei, "Behaviour of C-shaped angle shear connectors under monotonic and fully reversed cyclic loading: an experimental study," Materials \& Design, vol. 41, pp. 67-73, 2012. 
[18] K. Peng, J. Zeng, D. J. Armaghani, M. Hasanipanah, and Q. Chen, "A novel combination of gradient boosted tree and optimized ANN models for forecasting ground vibration due to quarry blasting," Natural Resources Research, vol. 2021, pp. 1-15, Article ID 098991, 2021.

[19] M. Hasanipanah, D. Meng, B. Keshtegar, N.-T. Trung, and D.-K. Thai, "Nonlinear models based on enhanced Kriging interpolation for prediction of rock joint shear strength," Neural Computing \& Applications, vol. 33, no. 9, pp. 42054215, 2021.

[20] W. Zhu, H. N. Rad, and M. Hasanipanah, "A chaos recurrent ANFIS optimized by PSO to predict ground vibration generated in rock blasting," Applied Soft Computing, vol. 108, Article ID 107434, 2021.

[21] M. Hasanipanah, B. Keshtegar, D.-K. Thai, and N.-T. Troung, "An ANN-adaptive dynamical harmony search algorithm to approximate the flyrock resulting from blasting," Engineering with Computers, vol. 2020, Article ID 011059, 13 pages, 2020.

[22] M. Hasanipanah and H. Bakhshandeh Amnieh, "A fuzzy rulebased approach to address uncertainty in risk assessment and prediction of blast-induced Flyrock in a quarry," Natural Resources Research, vol. 29, no. 2, pp. 669-689, 2020.

[23] M. Hasanipanah, W. Zhang, D. J. Armaghani, and H. Nikafshan Rad, "The potential application of a new intelligent based approach in predicting the tensile strength of rock," IEEE Access, vol. 8, pp. 57148-57157, 2020.

[24] D. J. Armaghani, D. Kumar, P. Samui, M. Hasanipanah, and B. Roy, "A novel approach for forecasting of ground vibrations resulting from blasting: modified particle swarm optimization coupled extreme learning machine," Engineering with Computers, vol. 2020, Article ID 00997x, 15 pages, 2020.

[25] A. Mohammed, S. Rafiq, P. Sihag, W. Mahmood, K. Ghafor, and W. Sarwar, "ANN, M5P-tree model, and nonlinear regression approaches to predict the compression strength of cement-based mortar modified by quicklime at various water/ cement ratios and curing times," Arabian Journal of Geosciences, vol. 13, no. 22, pp. 1-16, 2020.

[26] A. Mohammed, S. Rafiq, W. Mahmood et al., "Artificial Neural Network and NLR techniques to predict the rheological properties and compression strength of cement past modified with nanoclay," Ain Shams Engineering Journal, vol. 12, no. 2, pp. 1313-1328, 2021.

[27] A. Mohammed, S. Rafiq, P. Sihag, R. Kurda, and W. Mahmood, "Soft computing techniques: systematic multiscale models to predict the compressive strength of HVFA concrete based on mix proportions and curing times," Journal of Building Engineering, vol. 33, Article ID 101851, 2020.

[28] J. Huang, G. Shiva Kumar, J. Ren, J. Zhang, and Y. Sun, "Accurately predicting dynamic modulus of asphalt mixtures in low-temperature regions using hybrid artificial intelligence model," Construction and Building Materials, vol. 297, Article ID 123655, 2021.

[29] J. Huang, T. Duan, Y. Zhang, J. Liu, J. Zhang, and Y. Lei, "Predicting the permeability of pervious concrete based on the beetle antennae search algorithm and random forest model," Advances in Civil Engineering, vol. 2020, Article ID 8863181, 11 pages, 2020.

[30] J. Huang, Y. Sun, and J. Zhang, "Reduction of computational error by optimizing SVR kernel coefficients to simulate concrete compressive strength through the use of a human learning optimization algorithm," Engineering with Computers, vol. 2021, Article ID 01305x, 18 pages, 2021.
[31] P. Sarir, S.-L. Shen, Z.-F. Wang, J. Chen, S. Horpibulsuk, and B. T. Pham, "Optimum model for bearing capacity of concrete-steel columns with AI technology via incorporating the algorithms of IWO and ABC," Engineering with Computers, vol. 37, no. 2, pp. 797-807, 2021.

[32] D. Jahed Armaghani, V. Safari, A. Fahimifar, M. F. Mohd Amin, M. Monjezi, and M. A. Mohammadi, "Uniaxial compressive strength prediction through a new technique based on gene expression programming," Neural Computing \& Applications, vol. 30, no. 11, pp. 3523-3532, 2018.

[33] P. Sarir, J. Chen, P. G. Asteris, D. J. Armaghani, and M. M. Tahir, "Developing GEP tree-based, neuro-swarm, and whale optimization models for evaluation of bearing capacity of concrete-filled steel tube columns," Engineering with Computers, vol. 37, no. 1, pp. 1-19, 2021.

[34] R. S. Faradonbeh, M. Hasanipanah, H. B. Amnieh, D. J. Armaghani, and M. Monjezi, "Development of GP and GEP models to estimate an environmental issue induced by blasting operation," Environmental Monitoring and Assessment, vol. 190, no. 6, pp. 351-415, 2018.

[35] P. Sarir, S.-L. Shen, A. Arulrajah, and S. Horpibulsuk, "Concrete wedge and coarse sand coating shear connection system in GFRP concrete composite deck," Construction and Building Materials, vol. 114, pp. 650-655, 2016.

[36] M. Inel, "Modeling ultimate deformation capacity of RC columns using artificial neural networks," Engineering Structures, vol. 29, no. 3, pp. 329-335, 2007.

[37] C. Jørgensen, R. Grastveit, J. Garzón-Roca, I. Payá-Zaforteza, and J. M. Adam, "Bearing capacity of steel-caged RC columns under combined bending and axial loads: estimation based on Artificial Neural Networks," Engineering Structures, vol. 56, pp. 1262-1270, 2013.

[38] T. K. Sipos, V. Sigmund, and M. H. Nyarko, "Earthquake performance of infilled frames using neural networks and experimental database," Engineering Structures, vol. 51, pp. 113-127, 2013.

[39] B. Akbas, J. Shen, and T. A. Sabol, "Estimation of seismicinduced demands on column splices with a neural network model," Applied Soft Computing, vol. 11, no. 8, pp. 4820-4829, 2011.

[40] A. Ahmad, G. Kotsovou, D. M. Cotsovos, and N. D. Lagaros, "Assessing the accuracy of RC design code predictions through the use of artificial neural networks," International Journal of Advanced Structural Engineering, vol. 10, no. 4, pp. 349-365, 2018.

[41] A. Raza, Q. U. Z. Khan, and A. Ahmad, "Numerical investigation of load-carrying capacity of GFRP-reinforced rectangular concrete members using CDP model in ABAQUS," Advances in Civil Engineering, vol. 2019, Article ID 1745341, 21 pages, 2019.

[42] A. Ahmad, D. M. Cotsovos, and N. D. Lagaros, "Framework for the development of artificial neural networks for predicting the load carrying capacity of RC members," SN Applied Sciences, vol. 2, no. 4, pp. 1-21, 2020.

[43] A. Ahmad and A. Raza, "Reliability analysis of strength models for CFRP-confined concrete cylinders," Composite Structures, vol. 244, Article ID 112312, 2020.

[44] A. Ahmad and D. M. Cotsovos, "Reliability analysis of models for predicting T-beam response at ultimate limit response," Proceedings of the Institution of Civil Engineers - Structures and Buildings, vol. 2020, Article ID 00129, 23 pages, 2020.

[45] A. Ahmad, V. Plevris, and Q.-U.-Z. Khan, "Prediction of properties of FRP-confined concrete cylinders based on artificial neural networks," Crystals, vol. 10, no. 9, p. 811, 2020. 
[46] A. Ahmad and A. Raza, "Reliability analysis of strength models for CFRP-confined concrete cylinders," Composite Structures, vol. 244, Article ID 112312, 2020.

[47] A. Raza, Q. U. Z. Khan, and A. Ahmad, "Prediction of axial compressive strength for FRP-confined concrete compression members," KSCE Journal of Civil Engineering, vol. 24, no. 7, pp. 2099-2109, 2020.

[48] G. M. Kotsovou, A. Ahmad, D. M. Cotsovos, and N. D. Lagaros, "Reappraisal of methods for calculating flexural capacity of reinforced concrete members," Proceedings of the Institution of Civil Engineers - Structures and Buildings, vol. 173, no. 4, pp. 279-290, 2020.

[49] S. Lee and C. Lee, "Prediction of shear strength of FRPreinforced concrete flexural members without stirrups using artificial neural networks," Engineering Structures, vol. 61, pp. 99-112, 2014.

[50] R. Perera, D. Tarazona, A. Ruiz, and A. Martín, “Application of artificial intelligence techniques to predict the performance of RC beams shear strengthened with NSM FRP rods. Formulation of design equations," Composites Part B: Engineering, vol. 66, pp. 162-173, 2014.

[51] T. M. Pham and M. N. S. Hadi, "Predicting stress and strain of FRP-confined square/rectangular columns using artificial neural networks," Journal of Composites for Construction, vol. 18, no. 6, Article ID 04014019, 2014.

[52] P. Mehrabi, M. Shariati, K. Kabirifar et al., "Effect of pumice powder and nano-clay on the strength and permeability of fiber-reinforced pervious concrete incorporating recycled concrete aggregate," Construction and Building Materials, vol. 287, Article ID 122652, 2021.

[53] M. Shariati, D. J. Armaghani, M. Khandelwal, J. Zhou, and M. Khorami, "Assessment of longstanding effects of fly ash and silica fume on the compressive strength of concrete using extreme learning machine and artificial neural network," Journal of Advanced Engineering and Computation, vol. 5, no. 1, pp. 50-74, 2021.

[54] K. Nouri, N. R. Sulong, Z. Ibrahim, and M. Shariati, "Behaviour of novel stiffened angle shear connectors at ambient and elevated temperatures," Advanced Steel Construction, vol. 17, no. 1, pp. 28-38, 2021.

[55] S. Rajaei, P. Shoaei, M. Shariati et al., "Rubberized alkaliactivated slag mortar reinforced with polypropylene fibres for application in lightweight thermal insulating materials," Construction and Building Materials, vol. 270, Article ID 121430, 2021.

[56] M. Yazdani, K. Kabirifar, B. E. Frimpong, M. Shariati, M. Mirmozaffari, and A. Boskabadi, "Improving construction and demolition waste collection service in an urban area using a simheuristic approach: a case study in Sydney, Australia," Journal of Cleaner Production, vol. 280, Article ID 124138, 2021.

[57] M. Shariati, A. Shariati, N. T. Trung et al., "Alkali-activated slag (AAS) paste: correlation between durability and microstructural characteristics," Construction and Building Materials, vol. 267, Article ID 120886, 2021.

[58] A. Afshar, S. Jahandari, H. Rasekh, M. Shariati, A. Afshar, and A. Shokrgozar, "Corrosion resistance evaluation of rebars with various primers and coatings in concrete modified with different additives," Construction and Building Materials, vol. 262, Article ID 120034, 2020.

[59] A. Toghroli, P. Mehrabi, M. Shariati, N. T. Trung, S. Jahandari, and H. Rasekh, "Evaluating the use of recycled concrete aggregate and pozzolanic additives in fiber-reinforced pervious concrete with industrial and recycled fibers,"
Construction and Building Materials, vol. 252, Article ID 118997, 2020.

[60] M. Safa, P. A. Sari, M. Shariati et al., "Development of neurofuzzy and neuro-bee predictive models for prediction of the safety factor of eco-protection slopes," Physica A: Statistical Mechanics and Its Applications, vol. 550, Article ID 124046, 2020.

[61] M. Shariati, M. S. Mafipour, B. Ghahremani et al., "A novel hybrid extreme learning machine-grey wolf optimizer (ELMGWO) model to predict compressive strength of concrete with partial replacements for cement," Engineering with Computers, vol. 2020, pp. 1-23, Article ID 01081-0, 2020.

[62] M. Shariati, M. S. Mafipour, P. Mehrabi et al., "A novel approach to predict shear strength of tilted angle connectors using artificial intelligence techniques," Engineering with Computers, vol. 37, no. 3, pp. 2089-2109, 2021.

[63] M. Shariati, M. Grayeli, A. Shariati, and M. Naghipour, "Performance of composite frame consisting of steel beams and concrete filled tubes under fire loading," Steel and Composite Structures, vol. 36, no. 5, pp. 587-602, 2020.

[64] M. Shariati, M. Lagzian, S. Maleki, A. Shariati, and N. T. Trung, "Evaluation of seismic performance factors for tension-only braced frames," Steel and Composite Structures, vol. 35, no. 4, pp. 599-609, 2020.

[65] M. Shariati, F. Tahmasbi, P. Mehrabi, A. Bahadori, and A. Toghroli, "Monotonic behavior of $\mathrm{C}$ and $\mathrm{L}$ shaped angle shear connectors within steel-concrete composite beams: an experimental investigation," Smart Structures, vol. 35, no. 2, pp. 237-247, 2020.

[66] M. Naghipour and M. Mehrzadi, "Effect of progressive shear punch of a foundation on a reinforced concrete building behavior," Steel and Composite Structures, vol. 35, no. 2, pp. 279-294, 2020.

[67] L. Razavian, M. Naghipour, M. Shariati, and M. Safa, "Experimental study of the behavior of composite timber columns confined with hollow rectangular steel sections under compression," Structural Engineering \& Mechanics, vol. 74, no. 1, pp. 145-156, 2020.

[68] M. Shariati, M. S. Mafipour, P. Mehrabi et al., "Prediction of concrete strength in presence of furnace slag and fly ash using Hybrid ANN-GA (artificial neural network-genetic algorithm)," Smart Structures, vol. 25, no. 2, pp. 183-195, 2020.

[69] M. Naghipour, G. Yousofizinsaz, and M. Shariati, "Experimental study on axial compressive behavior of welded builtup CFT stub columns made by cold-formed sections with different welding lines," Steel and Composite Structures, vol. 34, no. 3, p. 347, 2020.

[70] D. J. Armaghani, F. Mirzaei, M. Shariati, N. T. Trung, M. Shariati, and D. Trnavac, "Hybrid ANN-based techniques in predicting cohesion of sandy-soil combined with fiber," Geomechanics Engineering, vol. 20, no. 3, pp. 191-205, 2020.

[71] M. Shariati, M. Ghorbani, M. Naghipour, N. Alinejad, and A. Toghroli, "The effect of RBS connection on energy absorption in tall buildings with braced tube frame system," Steel and Composite Structures, vol. 34, no. 3, pp. 393-407, 2020.

[72] M. Shariati, M. Naghipour, G. Yousofizinsaz, A. Toghroli, and N. P. Tabarestani, "Numerical study on the axial compressive behavior of built-up CFT columns considering different welding lines," Steel and Composite Structures, vol. 34, no. 3, pp. 377-391, 2020.

[73] M. Shariati and S. M. Azar, "Evaluating the impacts of using piles and geosynthetics in reducing the settlement of finegrained soils under static load," Geomechanics Engineering, vol. 20, no. 2, pp. 87-101, 2020. 
[74] M. Shariati, M. S. Mafipour, J. H. Haido, and S. T. Yousif, "Identification of the most influencing parameters on the properties of corroded concrete beams using an Adaptive Neuro-Fuzzy Inference System (ANFIS)," Steel and Composite Structures, vol. 34, no. 1, p. 155, 2020.

[75] M. Shariati, M. S. Mafipour, P. Mehrabi et al., "Application of a hybrid artificial neural network-particle swarm optimization (ANN-PSO) model in behavior prediction of channel shear connectors embedded in normal and high-strength concrete," Applied Sciences, vol. 9, no. 24, p. 5534, 2019.

[76] N. F. Hany, E. G. Hantouche, and M. H. Harajli, "Finite element modeling of FRP-confined concrete using modified concrete damaged plasticity," Engineering Structures, vol. 125, pp. 1-14, 2016.

[77] A. M. A. Ibrahim, M. F. M. Fahmy, and Z. Wu, "3D finite element modeling of bond-controlled behavior of steel and basalt FRP-reinforced concrete square bridge columns under lateral loading," Composite Structures, vol. 143, pp. 33-52, 2016.

[78] B. Alfarah, F. López-Almansa, and S. Oller, "New methodology for calculating damage variables evolution in Plastic Damage Model for RC structures," Engineering Structures, vol. 132, pp. 70-86, 2017.

[79] X. Zhang and Z. Deng, "Experimental study and theoretical analysis on axial compressive behavior of concrete columns reinforced with GFRP bars and PVA fibers," Construction and Building Materials, vol. 172, pp. 519-532, 2018.

[80] M. Elchalakani, A. Karrech, M. Dong, M. S. Mohamed Ali, and B. Yang, "Experiments and finite element analysis of GFRP reinforced geopolymer concrete rectangular columns subjected to concentric and eccentric axial loading," Structure, vol. 14, pp. 273-289, 2018.

[81] H. Sinaei, "Evaluation of reinforced concrete beam behaviour using finite element analysis by ABAQUS," Scientific Research and Essays, vol. 7, no. 21, pp. 2002-2009, 2012.

[82] M. Shariati, N. Ramli Sulong, and M. Arabnejad Khanouki, "Experimental and analytical study on channel shear connectors in light weight aggregate concrete," in Proceedings of the 4th International Conference on Steel Composite Structures, Sydney, Australia, December 2010.

[83] R. Rojas, "The backpropagation algorithm," in Neural Networks, pp. 151-184, Springer, Berlin, Germany, 1996.

[84] B. Hammer, "Neural networks," Academic Press Library in Signal Processing, vol. 1, pp. 817-855, 2014.

[85] Y. LeCun, L. Bottou, G. B. Orr, and K.-R. Müller, Efficient Backprop, pp. 1-44, springer, Berlin, Germany, 1998.

[86] A. Krogh and J. Vedelsby, "Neural network ensembles, cross validation, and active learning," Advances in Neural Information Processing Systems, vol. 7, pp. 21-238, 1995.

[87] A. Ahmad, G. Kotsovou, D. M. Cotsovos, and N. Lagaros, "Assessing the load carrying capacity of RC members through the use of artificial neural networks," in Proceedings of the HSTAM International Congress on Mechanics, Athens, Greece, May 2016.

[88] A. Ahmad, D. M. Cotsovos, and N. D. Lagaros, "Assessing the reliability of RC code predictions through the use of artificial neural networks," in The First International Conference on Structural Safety under Fire \& BlastCONFAB, Glasgow, UK, 2015.

[89] H.-T. Hu and W. C. Schnobrich, "Nonlinear analysis of cracked reinforced concrete," ACI Structural Journal, vol. 87, no. 2, pp. 199-207, 1990.
[90] H. Hibbitt, B. Karlsson, and P. J. D. S. S. C. P. Sorensen, Abaqus Analysis User's Manual Version 6.10, Hibbitt, Karlsson \& Sorensen, Inc., Providence, RI, USA, 2011.

[91] H. Sinaei, "Evaluation of reinforced concrete beam behaviour using finite element analysis by ABAQUS," vol. 7, no. 21, pp. 2002-2009, 2012.

[92] P. Kmiecik and M. Kamiński, "Modelling of reinforced concrete structures and composite structures with concrete strength degradation taken into consideration," Archives of Civil and Mechanical Engineering, vol. 11, no. 3, pp. 623-636, 2011.

[93] Abaqus, Abaqus 6.12 Documentation, Simulia, Dassault Systemes, Providence, RI, USA, 2012.

[94] A. P. Caldentey, P. Padilla Lavaselli, H. Corres Peiretti, and F. Ariñez Fernández, "Influence of stirrup detailing on punching shear strength of flat slabs," Engineering Structures, vol. 49 , pp. $855-865,2013$. 